\title{
The Development Benefits of Maternity Leave *
}

\author{
Kathleen M. Fallon \\ Stony Brook University \\ Alissa Mazar \\ McGill University \\ Liam Swiss \\ Memorial University
}

\author{
Final Submission Version \\ Forthcoming in World Development
}

\begin{abstract}
Within developing countries, studies addressing the effects of maternity benefits on fertility, infant/child health, and women's labor force participation are limited and provide contradictory findings. Yet, knowledge regarding the implementation of maternity provisions is essential, as such policies could significantly improve women and children's well-being. We add to this literature by using fixed effects panel regression from 1999 through 2012 across 121 developing countries to explore whether different types of maternity leave policies affect infant/child mortality rates, fertility, and women's labor force participation, and whether those effects are shaped by disparities in GDP per Capita and Secondary School Enrollment. Our findings demonstrate: 1 ) both infant and child mortality rates are expected to decline in countries that institute any leave policy, policies that last 12 weeks or longer, and policies that increase in duration and payment as a percentage of total annual salary, 2) fertility is expected to decline in countries that have higher weekly paid compensation, 3) maternity leave provisions decrease fertility and infant/child mortality rates most in countries with lower GDP per capita and countries with middle range secondary enrollment rates, and 4) labor force participation does not increase. Our results suggest that policy makers must consider the duration, compensation, and goals (addressing fertility versus mortality rates) of a policy alongside a country's economic development and secondary school enrollment when determining which maternity leave provisions to apply within developing-country contexts.
\end{abstract}

Key Words: Maternity Leave, Economic Development, Child Health, Fertility, Infant Mortality Rate

\footnotetext{
${ }^{*}$ Authors are listed alphabetically. All authors contributed equally to the manuscript. We thank John Shandra for detailed suggestions. The paper also benefited from feedback gathered from the Working Paper Workshop at Stony Brook University, the Sociology Development Conference at Brown University, and the Memorial University Employment Relations Speaker Series. Swiss is grateful to the Käte Hamburger Kolleg Centre for Global Cooperation, University of Duisburg-Essen, Germany for support of his work on this paper. The authors may be contacted at kathleen.fallon@stonybrook.edu, lswiss@mun.ca, or alissa.mazar@mail.mcgill.ca.
} 


\section{The Development Benefits of Maternity Leave}

\section{INTRODUCTION}

Better maternity leave policies, ${ }^{1}$ according to most studies, increase fertility (Engelhardt, Kogel, and Prskawetz 2004; Thévenon and Gauthier 2011), improve infant health (Coley and Lombardi 2013; Gregg, Washbrook, Propper, and Burgess 2005; Tanaka 2005), and increase women's labor force participation (Besamusca, Tijdens, Keune, and Steinmetz 2015; Matysiak and Weziak-Bialowolska 2013; Waldfogel 1998). Although these studies demonstrate the benefits of maternity leave policies, the majority focus on developed countries. Except for Nandi, Hajizadeh, Harper, Koski, Strumpr, and Heymann (2016), who examine the impact of maternity leave on infant mortality across 20 low and middle income countries, studies that focus on maternity leave in developing countries tend to be either non-empirical, focus on specific case studies, or use limited cross-national approaches (Chang 2004; Ilkkaracan 2012; Mehdizadeh 2013). These studies, of course, provide us with limited insight into the role of maternity leave. However, few are evidence based and often postulate competing arguments both for and against implementation (Hampel-Milagrosa 2011; Zveglich and Rodgers 2003). For example, some suggest that maternity leave provisions have positive consequences in developing countries by reducing infant and child mortality rates and by increasing women's labor force participation (Chang 2004; Mehdizadeh 2013). Yet, only one empirical study links maternity leave policies to improvements in child health, and other studies suggest that maternity provisions may have

\footnotetext{
${ }^{1}$ The literature on OECD countries mostly speaks of the impact of parental leave. If the parental leave policy is gender-blind, however, women will most likely take the leave instead of the male partner. In most developed countries, then, parental leave in practice remains maternity leave (Hennig, Gatermann, and Hagglund 2012). For the purpose of this paper, we focus on maternity leave, as this is typically the practice.
} 
negative or no consequences on women's labor force participation (Lee and Cho 2005;

Karshenas, Moghadam, and Alami 2014). Moreover, to our knowledge, there is no research on the impact of maternity provisions on fertility in developing nations.

We build on existing studies by examining the effectiveness of maternity leave crossnationally and within developing countries over time, with specific attention given to variations in economic (Gross Domestic Product per Capita) and social development (Secondary Educational Enrollments). Current studies on developed countries indicate that the desired effectiveness of maternity leave provisions differ within and across countries due to economic and educational disparities, in addition to the type of maternity policy implemented. We therefore argue that maternity leave policy effectiveness in developing countries will not only differ according to policy configurations (comparing different lengths and pay of leaves across countries), but will also be moderated by Gross Domestic Product (GDP) per capita and secondary educational enrollments - particularly since these two variables vary widely within and across developing countries. Additionally, because women and children should benefit most from maternity leave benefits, we focus on the effects of maternity leave on fertility, infant mortality, and child mortality rates - all proxies used to measure women and children's health. ${ }^{2}$ We also examine women's labor force participation, as its relationship with maternity leave is characterized by an inverted U-shape in developed countries ${ }^{3}$ (Akgunduz and Plantenga 2012; Baum and Ruhm 2016; Chatterji and Markowitz 2005; Genre, Salvador, and Lamo 2010; Misra,

\footnotetext{
${ }^{2}$ Infant and child mortality rates not only reflect children's health, but also capture broader development effects, such as access to such resources - as doctors and education (Lipton and Ravallion 1995; Sen 1999; Victoria et al. 2003). Measures of fertility similarly reflect levels of educational attainment (Buyinza and Hisali 2014; Musick, England, Edgington and Kangas 2009).

${ }^{3}$ First, in the absence maternity policies and of job guarantees, mothers tend to leave the labor market. Then, the availability of maternity leave and increases in its provisions leads to female labor force participation increasing by guaranteeing job continuity and the accumulation of human capital. Labor force participation, however, begins to decline once maternity leave becomes 'too long' as women become less attached to the labor force and lose human capital, which decreases the likelihood of returning to work in the long term.
} 
Budig, and Boeckmann 2011; Pettit and Hook 2005; Steiber and Haas 2012), but studies addressing this relationship in developing countries are limited and mixed (Chang 2004; Hampel-Milagrosa 2011). By looking at countries cross-nationally and longitudinally, we come closer to understanding how the implementation of maternity leave provisions in developing contexts has the potential to improve the health and well-being of women and children, which continue to be highlighted as central to advancing economic development - as evidenced, for example, within the United Nations Sustainable Development Goals (United Nations 2015). Specifically, we use fixed effects panel regression from 1999 through 2012 within 121 countries to explore how different maternity leave policies affect women's fertility rates, infant and under-five mortality, and women's labor force participation - with attention given to variation in social and economic development within and across countries. We find that fertility is lower in countries when adopting higher weekly paid maternity compensation. Both infant and child mortality rates are lower in countries that institute any leave policy, policies that last twelve weeks or longer, and policies that increase in duration and payment as a percentage of total annual salary (and at a faster rate in comparison to fertility). We similarly find that maternity provisions are moderated by levels of secondary school enrollment and GDP per capita. For example, predicted levels of fertility and infant/child mortality rates decrease when countries have lower GDP per capita and middle-range secondary enrollment rates. When maternity compensation is taken into account, and as it increases, then fertility and mortality rates also remain stable in nations with higher GDP and secondary enrollment rates. In terms of women's labor force participation, unlike developed countries, better maternity leave policies do not increase participation. Our findings suggest that policy makers must consider the length, duration, and goal (decreasing fertility or mortality rates) of a policy alongside a country's 
economic development and secondary school enrollment when determining which maternity leave benefits to apply within developing-country contexts.

\section{MATERNITY LEAVE POLICIES}

Because most of the literature addressing the effectiveness of maternity leave provisions tends to focus on developed countries, we begin by outlining the literature within developed country contexts to inform our hypotheses for developing countries. Specifically, these studies highlight how different maternity provision configurations, and how disparities in social and economic indicators within and between developed countries, influence the effectiveness of maternity leave policies. We then turn to research within developing countries, acknowledging the scarcity of studies in this area. We end by drawing from both literatures to theorize how different maternity provisions are expected to contribute to female labor force participation, fertility, and infant/child health in developing countries, and how these outcomes are likely moderated by education and GDP per capita.

\section{Developed Countries}

Although the literature addressing maternity leave policies within developed countries is broad and rich (Avendano, Berkman, Brugianvini,and Pasini 2015; Carneiro, Loken, and Salvanes 2015; Dagher, McGovern, and Dowd 2014; Daku, Raub, Heymann 2012; Low and SánchezMarcos 2015), for this paper, we focus on three prominent themes often tied to economic development: children's mortality rates (child health), female labor force participation, and women's fertility rates (Aassve and Lappegard 2009; Andersson 1999; Andersson, Baum and Ruhm 2016; Chatterji and Markowitz 2005; Engster and Stensota 2011; Hoem and Duvander 2006; Hoem 1993; Lalive and Zweimueller 2009; Vikat 2004). In developed countries, the 
relationship between infant and child mortality rates and maternity provisions are more uniformly negative (Ferrarini and Norstrom 2010; Ruhm 2000; Tanaka 2005); yet, maternity provisions' relationship to female labor force participation and fertility are less clear. Findings similarly demonstrate that disparities in maternity leave policies across countries, alongside variation of socio-economic status and educational levels among women, mediate the effects of maternity leave provisions.

Well-crafted maternity leave provisions are consistently linked to reduced infant and child mortality $^{4}$ (Ferrarini and Norstrom 2010; Ruhm 2000; Tanaka 2005). For example, Tanaka (2005), examining 18 OECD countries from 1969-2000, shows that longer and more generously paid maternity leave led to fewer low-weight babies and a decrease in infant mortality. Ruhm (2000), using panel data from sixteen European countries, supports these findings by demonstrating a strong positive correlation between paid parenting leaves and lower child mortality. Engster and Stensota (2011) similarly reveal that improved family policy support, including that of a paid parental leave, is associated with positive outcomes in terms of child mortality. The literature thus indicates that supportive maternity provisions are cost-effective policies that advance child health.

These health gains are often linked to facilitating women's re-entry into the workforce, improving women's financial situation, and increasing women's labor force participation (Baum and Ruhm 2016; Chatterji and Markowitz 2005). Well-crafted maternity leave policies, for example, are found to positively impact women's labor market outcomes as it provides a

\footnotetext{
${ }^{4}$ For this paper, we focus on mortality rates. However, the literature on developed countries points to positive effects of maternity policies on child health more generally (Clark et al. 1997; Gregg et al. 2005). For instance, speaking to the Australian case, Khanam, Nghiem, and Connelly (2016) find that maternity leave was significantly linked to prolonged breastfeeding, up-to-date immunizations, and even being negatively associated with the likelihood of children having asthma and bronchitis.
} 
framework to sustain women's attachment to the labor force, facilitating the accumulation of human capital (Shapiro and Mott 1994). Yet, its effect on female labor force participation is characterized by an inverted U-shape (Akgunduz and Plantenga 2012; Baum and Ruhm 2016; Chatterji and Markowitz 2005; Genre, Salvador, and Lamo 2010; Misra, Budig, and Boeckmann 2011; Pettit and Hook 2005; Steiber and Haas 2012), which is dependent on the duration and compensation of the leave implemented. Generally, moderate length, well-paid, and wage related leave improves female labor force participation and benefits (Boje and Ejrnaes 2012; Fagan and Norman 2012; Matysiak and Weziak-Bialowolska 2013), while long, low-paid, flat-rate leave decreases labour force participation and benefits (Gerecke 2013; Orloff 2009). ${ }^{6}$ Although optimal duration in relation to improving female labor force participation is debated, what is clear is that countries with less generous leave policies, like Anglo-Saxon countries, display more part-time work and longer interruptions from the workplace due to childbirth (Gornick, Meyers and Ross 1997; Thévenon and Gauthier 2011), while long, low-paid, flat-rate leave decreases labor force participation and benefits (Gerecke 2013; Orloff 2009), leading to the likelihood of more severe motherhood penalties. These studies demonstrate that different configurations of maternity leave benefits lead to varying levels of women's labor force participation.

\footnotetext{
${ }^{5}$ See footnote 3 .

${ }^{6}$ There is a consensus that the influence of maternity leave on female employment rates depicts an inverted U-shape (Ruhm 1998; Thévenon and Solaz 2013). What is considered an 'optimal' length of leave, however, remains unclear. Generally, moderate length, well-paid, and wage related leave improves female labour force participation and benefits (Boje and Ejrnaes 2012; Fagan and Norman 2012; Matysiak and Weziak-Bialowolska 2013), while long, low-paid, flat-rate leave decreases labour force participation and benefits (Gerecke 2013; Orloff 2009). Concerning duration, longer leaves have been found to reduce women's employment and earning outcomes (De Henau, Meulders and O'Dorchai 2011; Rønsen and Sundström 2002). More specifically, some studies find the positive effect to be maximized around 6 to 8 months (Genre et al. 2010; Akgunduz and Plantenga 2012) whereas others suggest an optimal duration of 18 months (Misra et al. 2011) or even around three years (Pettit and Hook 2005). Relating to length, Keck and Saraceno (2013) suggest that long paid maternity leaves do not have a negative impact on employment. They argue that long leaves with even some payment allows mothers time to create appropriate work/care arrangements compared to short leaves, however well paid. Korpi et al. (2013) similarly find that generous provisions result in women with lower educational levels improving their economic standing through participation in the labor force.
} 
In terms of fertility, differences in maternity leave policy across countries do not always match the intended patterns, often meant to increase fertility levels. The paragon examples of the positive impacts of maternity provisions on fertility were found in Sweden (Andersson 1999; Andersson, Hoem and Duvander 2006; Hoem 1993) and Austria (Lalive and Zweimueller 2009). Relatedly, the introduction of parental provisions had a positive influence on fertility in Finland, Norway, and France (Aassve and Lappegard 2009; Vikat 2004). Yet, despite some evidence of the positive impact of maternity leave on fertility, results are not consistent. For example, despite France providing many more supportive family policies than Britain, Britain's fertility still aligns closely to France in recent decades (Gauthier 2007). In addition, while Quebec provides more supportive family policy than other Canadian provinces, its fertility has remained lower or equal to that of the rest of Canada since the mid-1960s. ${ }^{7}$ Similarly, in areas characterized by lengthy mandatory maternity leave in tandem with minimal and flat rate benefit packages, such as Southern Europe and in some areas of Eastern Europe, birthrates fell (Thévenon 2008). ${ }^{8}$ These examples suggest that, while configurations of maternity leave benefits may contribute to differing outcomes, other economic and social indicators must also be key contributors to the patterns. Additionally, fertility may be subject to a threshold effect, requiring benefits to attain a minimum level before achieving an effect and/or the effect of benefits reaching a plateau beyond a certain point (Gauthier 2007).

Effects of maternity provisions on child health, fertility, and women's labor force participation are further moderated by the socio-economic status (Korpi et al. 2013; Mandel and Semyonov 2006) and educational levels of women - leading to disparities in policy outcomes

\footnotetext{
${ }^{7}$ Evidence, however, suggests that fertility in Quebec may have been even lower in the absence of these policies (Milligan 2002).

${ }^{8}$ For instance, policies of Southern Europe and in some areas of Eastern Europe, which are characterized by lengthy mandatory maternity leave in tandem with minimal and flat rate benefit packages, resulted in falling birthrates (Thévenon 2008).
} 
(Karaçam 2008). Mandel (2010) demonstrates how that the positive or negative impact of maternity leave on employment is conditioned by the working mother's relative advantage or disadvantage related to their economic class and education. She specifically finds support for the negative implications maternity leave policies have for the economic attainments of advantaged women while having positive implications for less advantaged women. Indeed, as women are a heterogeneous group, the socio-economic and educational status of women mediates the impact of maternity provisions on employment. ${ }^{9}$ Additionally, although there is a linear and positive relationship between maternity provisions and infant/child health, which mothers benefit most dramatically from the provisions is often determined by education levels and economic status. For instance, mothers with lower education are less likely to be able to afford to take unpaid time off and may have more physically demanding jobs. Indeed, these mothers and their children are more likely to benefit from maternity provisions (Steams 2015). Similarly, mothers' educational levels and socio-economic status mediate how maternity provisions impact fertility - as there is a U-shape relationship between fertility and socio-economic status - whereby women of average socio-economic status prefer their income over maternity provisions while women of high socioeconomic status have greater access to daycare (Bratti 2001; Del Boca and Locatelli 2006).

Using findings in the developed context to inform hypotheses in the developing context, it is evident that there is a non-uniform effect of maternity provisions on infant and child health, female labor force participation, and rates of fertility. Generally, maternity leave may positively impact fertility, infant/child health, and female labor force participation by lessening the

\footnotetext{
${ }^{9}$ The differences in effect are based on discriminatory employer behavior being influenced by women's occupational position. For instance, firms favor more stable and productive employees for jobs with high training costs (Aigner and Cain 1977). With limited information on individual applicants, employers discriminate against entire groups considered less productive. Since the cost of a mismatch is trivial for jobs with little or no job training, the risk of statistical discrimination mainly applies to women with high human capital, who are potential candidates for elite positions, or positions that offer career mobility (Tomaskovic-Devey 1993)
} 
opportunity costs of having children, giving women the time necessary to care for infants, and guaranteeing job continuity. ${ }^{10}$ Nonetheless, the effectiveness of maternity leave is complicated by the type of leave implemented and other economic and social determinants. Since the outcomes of maternity provisions are not similar within and across developed countries, the effects of maternity provisions within and across developing countries should not be expected to display a uniform relationship. Rather, we expect to find that the effects of maternity provisions on child mortality, women's labor force participation, and fertility in developing countries will depend on national income levels, secondary educational enrollment levels, and type of maternity leave policy implemented.

\section{Developing Countries}

In contrast to the literature on developed countries, studies examining the outcomes of maternity provisions in developing countries are less robust, particularly regarding key development indicators like fertility and infant/child mortality rates. Findings concerning women's labor force participation rates are also limited and mixed (Chang 2004; Lee and Cho 2005). Moreover, no studies explore how economic and educational disparities across countries may influence the effectiveness of maternity leave policies. When studies do focus on maternity provisions in the developing context, they tend to be either non-empirical, depend on limited case studies, or use limited cross-national approaches. For instance, unlike research on developed countries, to our knowledge, no studies have examined the impact of maternity leave provisions on fertility in a developing context. It could be expected that as maternity leave improves lessening the opportunity costs of children - fertility may also increase. Nonetheless, like developed countries, the various socio-economic realities in developing countries may also

\footnotetext{
${ }^{10}$ This was also corroborated by the US studies in the late 1980s and 1990s, which allowed one to observe that mothers with leave benefits returned to work faster than women who lost work once they had a child (Berger and Waldfogel 2004; Hofferth and Curtin 2006; Klerman and Leibowitz 1999).
} 
impact the outcome of maternity provisions. For example, with higher initial fertility rates in developing countries, maternity provisions may lead to declining fertility as female job security and continuity increases. As women's time is given increasing economic value through maternity provisions, the need to have many children - who traditionally provide financial support to women as they age - may decrease (Germain 1975; Wickrama and Lorenze 2002).

In terms of infant and child mortality rates, some research mirrors the developed-country context suggesting that maternity provisions, due to their potential in helping reconcile workfamily conflicts, improves the health of infants in terms of mortality. ${ }^{11}$ For instance, Mehdizadeh's (2013) work using four case studies - Iran, Qatar, Tunisia, and Turkey - suggests that without the extension and increasing implementation of policies which enable work-family reconciliation, like mandated maternity provisions, it will be difficult to achieve the Millennium Development Goals, ${ }^{12}$ one of which is to reduce infant mortality rates. Mehdizadeh (2013) specifically notes that infants whose mothers have access to maternity leave will benefit from more frequent and extended breast-feeding. Unfortunately, Mehdizadeh (2013) does not empirically test these relationships and does not complicate such postulations by highlighting how other socio-economic indicators may mediate the effects. Nandi et al. (2016), however, use a difference-in-differences approach via the Demographic and Health Surveys to examine 20 low- and middle-income countries (LMICs) from 2000-2008 and find that each additional month of paid maternity is associated with 7.9 fewer infant deaths per 1,000 live births. Their study suggests that there is potential to improve infant health by increasing the duration of paid

\footnotetext{
${ }^{11}$ Many studies focusing on infant and child health in developing countries suggest, although do not test, that expanding maternity provisions will result in increasing infant and child health, primarily through increased length of breastfeeding (Batal, Boulghourjian, Abdallah, Affi 2006; Victora, Aquino, do Carmo, Monteiro, Barros, Szwarcwald 2011).

${ }^{12}$ The United Nations Millennium Development Goals include: reducing infant mortality rates; improving mothers' health; ensuring women's employment; increasing women's financial security and; improving equal opportunity and treatment in the workplace. This is to promote the gender equality and empowerment of women (Mehdizadeh 2013).
} 
maternity leave in LMICs. Yet, since their study only focuses on 20 LMICs, they caution that their findings may not be generalizable beyond these countries. In addition, their study does not explore varying levels of economic development in developing countries nor does it concentrate on the level of compensation as impacting the outcome of maternity leave provisions on infant well-being. Ultimately, the quantitative empirical literature concerning the impact of maternity leave on child well-being, and infant mortality rates more specifically, in a developing context is scarce. Yet, given that mortality rates are a strong indicator of children's well-being and a country's general development, these variables are key in assessing the effectiveness of maternity leave and should be examined further.

In relation to labor force participation, some research on developing countries also echoes the literature in the developed context suggesting that maternity leave can improve women's participation. For example, based on a case study of Taiwan, Van der Meulen Rodgers (1999) argues that mandated maternity benefits promote women's labor force attachment. Nonetheless, this study does not employ methods which allow for causal inference. These positive findings are supported, however, by Chang's (2004) study on cross-national variation of sex segregation in 16 developing countries. Chang's findings demonstrate that maternity leave facilitates women's access to the labor market by enabling women to more effectively combine the roles of mother and laborer. In essence, Chang finds that maternity leave integrates women across the occupational structure as it facilitates women's continuous labor force participation and increases their human capital, offering women a better position to compete with men for jobs. Other studies note, however, that employment and social protections targeted at women may inhibit their entry into the labor market (Hampel-Milagrosa 2011). In developing countries, it is often the employer rather than the state that is burdened with the cost of the leave, which can result in 
employer reluctance to hire females since they may be more costly (Karshenas, Moghadam, and Alami 2014; Lee and Cho 2005). Although current reports and articles offer competing arguments, many postulate relationships based upon little or no empirical evidence. Indeed, there is a scarcity of studies (all but Chang (2004)), which allow for causal inference and systematically assess the effect of maternity leave policy on female labor force participation.

Female labor force participation rates are nonetheless high in many developing countries since women's employment is driven by poverty and necessity, tending to be in agriculture or home-based production (Verick 2014). This differs in middle-income countries, where economic activity tends to shift to more industrial production - often placing limits on women's access to the labor force. As middle income countries advance and the service sector grows (along with education improving and fertility rates falling), however, women increasingly join the labor force again (Goldin 1995; Lincove 2008; Pampel and Tanaka 1986; Kabeer and Mahmud 2004). Indeed, in a developing context, maternity provisions may not have a significant impact of female labor force participation, especially if the country has low levels of GDP per capita, since women tend to already be in the labor force.

Together with the lack of empirical evidence concerning the impact of maternity provisions on development indicators, there is also large variation in development levels within and across developing countries (Hausmann, Tyson, Bekhouche, and Zahidi 2014). Like developed countries, which are heterogeneous and characterized by non-uniform outcomes from maternity provisions, it is plausible that varying levels of social and economic development may affect the benefits of maternity leave provisions in the developing context. Indeed, differing levels of inequality found across developing countries will likely impact the effectiveness of maternity provisions to improve development indicators. 
In developing countries, GDP per capita may be particularly salient due to its relationship to the informal economy, where GDP per capita is found to be negatively associated to the size of the informal sector. For instance, Loayza and Rigolini (2006) find that the informal sector is larger in countries that have lower GDP per capita while Williams (2014) finds a strong negative relationship between the size of the informal sector and the level of wealth in a country, as measured by GDP per capita. Given the variation in levels of GDP per capita across developing countries - as, in 2012, Ethiopia recorded a GDP per capita of $\$ 469.80$, India having a GDP per capita of $\$ 1,444.30$, and Jamaica having a GDP per capita of $\$ 5,445.90$ - the size of the informal economy will likely vary widely across developing countries as well (World Bank 2016). Concerning maternity provisions, the size of the informal sector will impact the amount of women eligible for maternity leave since being part of the formal economy is a prerequisite (Chen, Sebstad, and O'Connell 1999; Ginneken 2003). A larger informal economy will result in fewer women being eligible for maternity leave coverage, since many women in developing nations work in the informal sector (Harriss-White 2010; Tzannatos 1999; Wekwete 2014). For instance, in Turkey as much as 85 percent of employed women with no schooling and 58 percent of those with primary schooling have no access to social security through their job, which means they do not have the option of maternity leave (Ilkkaracan 2012). On the flipside, however, countries with the lowest GDP per capita and larger informal sectors often have the highest infant/child mortality rates and the highest fertility rates. For example, in 2012, Afghanistan had a GDP per capita of $\$ 690.80$ and an infant mortality rate of 72 per 1,000 live births while also having a fertility rate of 5.3. Chad also recorded a GDP per capita of $\$ 972.70$ and had an infant mortality rate of 90 per 1,000 live births with a fertility rate of 6.4 while Cote d'Ivoire had a GDP of $\$ 1,281.40$, infant mortality of 73 per 1,000, and a fertility rate of 5.1 (World Bank 2016). 
We, therefore, hypothesize that although we might expect countries with lower GDP per capita (suggesting larger informal economies) to receive fewer benefits from maternity provisions, in reality, countries with lower GDP per capita should experience the greatest 'shock' benefit from maternity leave provisions and have the most to gain due to their high levels of fertility and infant/child mortality rates. Due to job security provided through the leave, women with access to maternity benefits would have a decreased need to have more children and they would have more time to focus on the health of their children.

Similarly, secondary educational enrollments across developing countries vary widely, and have improved over time, also possibly influencing maternity leave provisions. For instance, Barro and Lee (2013) find that developing countries within Sub-Saharan Africa and South-east Asia have the lowest levels of education, at 5.3 years of education attainment on average, compared to the average of 7.2 years for developing countries. They also report varying levels of education based on gender throughout developing countries, where, for instance, in South-east Asia schooling among females to males remains below 70 percent, whereas the average for developing countries is 85.9 percent. Similarly, Cohen and Soto (2007) highlight differences by showing that developing countries in Central and Eastern Europe had the most education on average, with 7.8 years in 2000, while Sub-Saharan Africa had the lowest of 3.9 years in 2000 . Like GDP per capita, we hypothesize that, although we might expect countries with higher education levels to have better maternity leave outcomes (with greater access to the formal sector), in actuality, countries with lower levels of secondary education (regardless of the existing informal sector) will see the most dramatic effects since these countries also have some of the highest fertility and infant/child mortality rates. We expect countries to reach a certain threshold for secondary enrollment levels before these effects are observed, since a certain 
percentage of women able to enter the formal market is needed before these benefits occur. Moreover, like findings in developed countries, maternity provisions may more dramatically benefit these women by increasing their labor force attachment, increasing the economic value of their time, and decreasing the incentive to have more children. This would provide job security for women- who potentially did not have such security prior - allowing for decreases in fertility. This would also allow mothers who once had no option but to work while being unable to pay for alternative care arrangements to care for their infants, resulting in health improvements.

Finally, the type of maternity provisions implemented may influence their effectiveness. As seen in developed countries, the length of and compensation during the leave may determine whether women's labor force participation, fertility, and infant/child health increases (Galtry and Callister 2005; Lalive and Zweimueller 2009; Staehelin, Bertea, Stutz 2007; Thévenon and Solaz 2013). Although other studies on developing countries do not account for variations in types of maternity leave policies, we attempt to account for these by comparing different measures of maternity provisions to assess if one type is better than others in developing country contexts.

Based on the literature review of both developed and developing countries, we suggest the following hypotheses concerning maternity provisions and their impact on female labor force participation, infant/child mortality, and fertility across developing countries:

H1. Improved maternity provisions will have a small effect, if any, on labor force participation since female labor force participation tends to be high in developing countries.

H2. Improved maternity provisions will improve child health as it increases mothers' ability, in terms of both time and money, to care for their children. 
a. Countries with lower levels of GDP per capita will experience the greatest impact.

b. Countries with low (yet attaining a minimum threshold) to middle secondary enrollment will experience the greatest impact.

H3. Improved maternity provisions will decrease fertility because this will increase women's economic value outside of childbearing.

a. Countries with lower levels of GDP per capita will experience the greatest impact.

b. Countries with lower secondary education will experience the greatest impact.

H4. All of the above hypotheses will be influenced by the compensation and duration of maternity provisions provided to mothers.

\section{METHODS}

To assess the effects of maternity leave policies on fertility, women's labor force participation, infant and under-five mortality, we analyze a longitudinal sample of countries over a 13-year period using a cross-sectional time series approach. Based on the results of a SargenHansen test, we use a fixed-effects model that takes the form:

$$
y_{i t}=\beta_{0}+\beta_{1} x_{i t}+\alpha_{i}+\varepsilon_{i t}
$$

In this equation $\beta_{0}$ is the time varying intercept, $\beta_{1}$ is a vector of coefficients, and $x_{i t}$ is a vector of time- and country-varying characteristics, $\alpha_{i}$ is the fixed characteristics of a given country, and $\varepsilon_{i t}$ is the error term varying with time (Allison 2009). Our models also use clustered standard errors to correct for unobserved heterogeneity and the presence of a first-order 
autoregressive disturbance in our panels. ${ }^{13}$ In separate models testing the moderating effects of

GDP per capita and secondary school enrollment we add an interaction term for each moderator:

$$
y_{i t}=\beta_{0}+\beta_{1} x_{1 i t}+\beta_{2} x_{2 i t}+\beta_{3} x_{1 i t} x_{2 i t}+\cdots+\alpha_{i}+\varepsilon_{i t}
$$

Here, in addition to the terms above, $\beta_{2}$ is a vector of coefficients indicating the main effect of the moderating variable ( $x_{2 i t}$ ), while $\beta_{3}$ is the vector of coefficients for the interaction term of the maternity leave measure and the moderator.

\section{Data}

Due to data availability, our largest sample consists of observations for 121 low- and middleincome countries from 1999 until $2012 .{ }^{14}$ One country, Russia, was dropped from the sample as an outlier, with a maternity leave duration of 100 weeks. The range of years examined was based on the availability of data concerning changes to maternity leave legislation through time, from 1994-2011, provided by the ILO (ILO 2013). We define a country as developing when it is coded as low income or middle-income within the World Bank Development Indicators in 1994 (GNI per capita $\leq 8,995$ ). The dataset is an unbalanced panel with observations taken every five years, and after three years for the final 2012 observation. The maximum number of

\footnotetext{
${ }^{13}$ Our results are robust to alternate specification. We conduct the same analysis using random effects panel regression and yield results which echo those presented below in Tables $2 \& 3$.

${ }^{14}$ Our 121 country sample includes: Albania, Algeria, Angola, Antigua \& Barbuda, Argentina, Armenia, Azerbaijan, Bangladesh, Barbados, Belarus, Belize, Benin, Bhutan, Bolivia, Botswana, Brazil, Bulgaria, Burkina Faso, Burundi, Cameroon, Central African Republic, Chad, Chile, China, Colombia, Comoros, Congo (Republic), Congo (Democratic Republic), Costa Rica, Cote d'Ivoire, Cuba, Djibouti, Dominica, Dominican Republic, Ecuador, Egypt, El Salvador, Equatorial Guinea, Eritrea, Ethiopia, Fiji, Gabon, Gambia, Georgia, Ghana, Grenada, Guatemala, Guinea, Guinea-Bissau, Guyana, Honduras, Hungary, India, Indonesia, Jordan, Kazakhstan, Kenya, Laos, Latvia, Lebanon, Lesotho, Lithuania, Macedonia, Madagascar, Malawi, Malaysia, Mali, Mauritania, Mauritius, Mexico, Micronesia, Moldova, Mongolia, Morocco, Mozambique, Namibia, Nepal, Nicaragua, Niger, Nigeria, Oman, Pakistan, Palau, Panama, Papua New Guinea, Peru, Philippines, Poland, Romania, Rwanda, Samoa, Saudi Arabia, Senegal, Seychelles, Sierra Leone, Slovakia, Slovenia, Solomon Islands, South Africa, Sri Lanka, St. Kitts \& Nevis, St. Vincent \& the Grenadines, Suriname, Swaziland, Syria, Tajikistan, Tanzania, Thailand, Togo, Trinidad \& Tobago, Tunisia, Turkey, Uganda, Ukraine, Uruguay, Uzbekistan, Vanuatu, Venezuela, Yemen, Zambia, and Zimbabwe.
} 
observations for a country is 4 and the minimum is 1 . To account for time of passage of maternity provision to the time of implementation, we use the independent variables to predict a five-year lead of the dependent variables, which represents that mean electoral term in which a provision would be passed and implemented. ${ }^{15}$

\section{[TABLE 1 ABOUT HERE]}

\section{Maternity Provisions}

Our key independent variable, from the International Labour Organization (ILO 2013), is maternity leave. One innovation of this article is that we measure maternity leave in several ways. ${ }^{16}$ These are:

(1) Any maternity leave: a dummy variable recording the presence of any formal maternity leave policy in a country; 109 of our 121 sample countries have maternity leave at one point during our period of analysis;

(2) Any maternity leave with duration >12 weeks: a dummy variable indicating leaves of 12 weeks or greater; only 93 of 121 countries in our sample ever have maternity leave of this duration;

(3) Maternity leave compensation (weekly): the percentage of salary paid on a weekly basis if a maternity leave policy exists. The median amount is 100 percent, with a mean of approximately 85 percent pay; and

(4) Maternity leave compensation (annual): the percentage of annual salary mothers can expect to receive as maternity leave compensation. We calculate annual maternity compensation variable by multiplying the number of weeks of maternity leave as a

\footnotetext{
${ }^{15}$ Thus regressions predict the values of dependent variables in 1999 based on independent variables measures in 1994 , establishing temporal priority in the analysis.

${ }^{16}$ We also ran analyses which included a continuous measure of maternity leave duration in weeks, but opted to measure this instead through a dummy variable indicating leaves of 12 weeks' duration or more.
} 
proportion of the year (weeks/52) by the percentage of salary paid to arrive at an overall percentage of annual salary. The median maternity compensation amount in our sample is 23.1 percent of an annual salary, with values ranging from zero compensation up to as much as 55.4 percent compensation.

Of the 121 countries in our sample, 36 experience changes in the levels of maternity compensation and/or duration during the period of our study, with most of those (32) experiencing some increase in either compensation or duration between time points; while 4 experience only decreases in annual compensation.

\section{Dependent Variables}

The dependent variables included are those highlighted within the literature review. Wellcrafted maternity provisions have been found to improve women's labor force participation and increase fertility rates. Similarly, they have been found to decrease infant and child mortality rates. These variables are from the International Labor Organization (ILO 2016) and the World Bank's Development Indicators (WDI) 2015 database (World Bank 2015). Summary statistics for each of these measures are reflected in Table 1 above.

Women's Labor Force Participation: Female labor force participation, which is inclusive of the informal sector, ${ }^{17}$ is based on women who are supplying labor to produce goods and services in a given year. To account for women who are considered of reproductive age, we use a measure of the percentage of women who are economically active and are 15-49 years of age (ILO 2016).

\footnotetext{
${ }^{17}$ Ideally, we would have liked to include a variable that measures the informal labor force independently of female labor force participation. Unfortunately, limited data availability prevents us from doing so (ILO 2011).
} 
Fertility Rate: The fertility rate is defined as the predicted total number of children ever born to a woman if she were to survive through the end of her child-bearing years.

Infant Mortality Rate: This is the number of children who die before one year age, per 1, 000 live births a year.

Under-Five Mortality Rate: This is the number of children who die before age five, per 1, 000 live births a year.

\section{Moderating Variables}

To test our hypotheses regarding the moderating effects of national income and education on the effects of maternity provisions, we interact the maternity leave measures with two variables:

GDP per capita: We account for level of economic development using GDP per capita in constant 2005 dollar terms. To account for skewness we include the natural log of GDP in our analysis.

School Enrollment, Secondary Education: We measure secondary education enrollment using the gross enrollment in secondary education. Regardless of age, this is contrasted against the percentage of the population who are of the official age to attend secondary school. Secondary gross enrollment ratios can also exceed 100 percent due to the inclusion of over-aged and underaged students.

\section{Control Variables}

Predictors of our dependent variables are often linked to development when addressing low- and middle-income countries. Therefore, our control variables, alongside the various maternity 
provisions, all account for some level of development - whether economic or social. Like the dependent variables, these control variables were also collected from the World Bank's Development Indicators (WDI) 2015 database (World Bank 2015).

Net Official Development Assistance/Official Assistance per capita: Based on constant 2011 US dollars, this involves disbursements of loans made on concessional terms, which are net repayment of principal, and grants by: 1) official agencies of the Development Assistance Committee (DAC) 2) by multilateral institutions and 3) by non-DAC countries. This is to promote economic welfare and development for eligible countries and territories. The percentage is found by dividing the net ODA/OA received by an estimate of the midyear population.

Democracy: To measure the level of democracy in our sample countries we include the Polity IV democracy/authoritarianism score. This measure ranges from most authoritarian, at -10 , to most democratic, at 10, with a median in our sample of 5.

Health Spending: Because health development indicators are likely to be related to the level of health spending in a country, we include a measure of total health expenditure as a percent of GDP. Median spending in our sample is 5.36 percent of GDP.

\section{[TABLE 2 ABOUT HERE]}

\section{Results}

\section{Primary Analysis}

Our primary analysis regresses each of the four dependent variables on the maternity leave measures in bivariate regressions, and then in full models including controls. ${ }^{18}$ In the tables

\footnotetext{
${ }^{18} \mathrm{We}$ also tested models for annual salary compensation including a quadratic term to assess whether a curvilinear relationship exists, but the results were non-significant.
} 
below, we report only those full models in which an association between maternity leave and our outcome variables is apparent. ${ }^{19}$

Table 2 shows the effect of maternity benefits on two of our four dependent variables: female labor force participation and fertility. Contrary to the research literature from highincome countries, we find that none of the maternity provisions in our analysis was associated with increases in women's labor force participation. We include Models 1 and 2 of Table 2 only to indicate this non-finding. ${ }^{20}$ Models 3 and 4 in Table 2 show the only models where maternity leave measures were correlated with fertility. We show two models for this maternity leave measure - one controlling for secondary enrollment and the other for GDP per capita. ${ }^{21}$ The results reveal that only weekly maternity leave compensation is associated with reductions in fertility rates at a $p<0.05$ level. None of the other measures of maternity leave duration or compensation are associated with changes in fertility rates five years later. In models 3 and 4, net of all other independent variables, the effect of maternity compensation is modest, but noticeable. To illustrate this relationship in Model 3, a 25 percentage point increase (approximately one standard deviation) in weekly maternity leave compensation predicts a 0.125 birth reduction in fertility rate, all else equal, while the mean level of weekly compensation (85.1 percent) would predict a reduction in fertility of nearly two-thirds of a birth (-0.59) in Model 4. The other variables in Table 2 are consistent with the literature and show that labor force participation and fertility are associated with levels of economic and social development. The model fit for labor force participation is very limited as indicated by the low $\mathrm{R}^{2}$ values, while the

\footnotetext{
${ }^{19}$ Sample size varies across models because of data availability of the different maternity leave measures and for the dependent variables.

${ }^{20}$ To account for the possibility of a "ceiling effect" of female labor force participation distorting our model results, we also conducted a longitudinal Tobit model that accounts for the upper limit of the dependent variable. These results mirrored our main analysis, revealing no statistically significant association between maternity compensation and female labor force participation.

${ }^{21}$ Owing to the high correlation between these two measures, they cannot be included in the same model without causing collinearity.
} 
overall model $\mathrm{R}^{2}$ in the fertility models ranges from 0.528 to 0.670 indicating a more compelling model overall.

\section{[TABLE 3 ABOUT HERE]}

Table 3 shows the effects of maternity leave on the two mortality variables. For these analyses, we again regressed the mortality measures on all of our maternity leave measures. Only those models with significant estimates for maternity leave are shown. With both infant and under-five mortality our results support the hypotheses that maternity leave is associated with reductions in mortality. Declines in infant mortality are predicted by the presence of any maternity leave policy (Model 1), the presence of leave policies greater than 12 weeks in duration (Model 2), and with increases in the amount of annual maternity leave compensation (Model 3). For instance, using the results in Model 3, we estimate that that a 10-percentage point increase in maternity leave compensation in terms of annual salary would predict a more-than 4 birth per 1,000 decrease in infant mortality rate. The results are similar for under-five mortality. Both any maternity leave policy (Model 4) and those with a duration of 12 weeks or greater (Model 5) predict significant reductions in child mortality. In Model 6, a one standard deviation (25 point) increase in weekly salary compensation predicts more than 9 fewer deaths per 1,000 live births of children under five years of age. Likewise, a 10-point increase in annual salary compensation predicts a similar (8.89) death decrease in the child mortality rate. These findings demonstrate a clear relationship between maternity leave compensation and improvements in infant and child mortality.

\section{Moderating Effects of National Income and Education}


In the second stage of our analysis, we test our hypotheses on how the benefits of maternity leave are moderated by changing levels of social and economic development through a series of interaction models. We analyzed interactions of four maternity measures (any leave; leave of $12+$ weeks; weekly compensation; and annual compensation) with both GDP per capita and secondary enrollment, resulting in 24 separate interaction models. We present only a selection of these in Table 4 below. ${ }^{22}$

\section{[TABLE 4 ABOUT HERE]}

Through these interaction models we examine how the effect of improved maternity compensation are moderated by economic development and education. ${ }^{23}$ Our analysis tests the propositions about economic development and education we propose earlier in the article to assess whether maternity leave's beneficial effects are most notable in low-income, loweducation contexts or in higher-income, more highly educated settings. To assist in interpretation of the interaction effects, we graph the changing marginal effects of each of the maternity measures by varying levels of GDP per capita and secondary enrollment in Figures 1 and 2 below. $^{24}$

\section{[FIGURE 1 ABOUT HERE]}

\section{[FIGURE 2 ABOUT HERE]}

For the mortality measures, we see that maternity leave policies and compensation are both associated with reduced mortality at the lowest level of GDP per capita and secondary

\footnotetext{
22 Other model results are available upon request.

${ }^{23} \mathrm{We}$ conducted interaction models for each of our four dependent variables, but only report the significant interactions in Table 4.

${ }^{24}$ The figures show 22 of 24 interaction estimates and include only those where the marginal effect of the maternity measure was significantly different than zero.
} 
enrollment, but that these effects are moderated by increasing national income and education levels. In the case of fertility, our results show that weekly maternity compensation is associated with reduced numbers of births per women, but that this effect is attenuated as countries' level of economic development and the rate of secondary enrollment increase. ${ }^{25}$

As GDP per capita increases, we see in Figure 1 that the magnitude of the effect of the maternity measures on fertility rate approaches zero. In countries with less than median GDP per capita, maternity compensation reduces mortality and fertility rates, whereas when countries are wealthier, the effect of maternity compensation is not different than zero. This supports our hypothesis that the effects of maternity leave are most direct in lower-income countries.

A similar pattern emerges in Figure 2, where at levels of secondary enrollment below approximately 50 percent, the effect of maternity policies and compensation on fertility rate is negative and different than zero. However, the marginal effect of maternity compensation edges closer to zero as education levels grow, meaning that the effect of maternity compensation is diminished to the point of being indistinguishable from zero in more highly educated countries. In countries with higher levels of education, the presence of maternity policies actually predicts slight increases in fertility rates. ${ }^{26}$ These findings indicate that maternity benefits contribute to reduced fertility most acutely in countries with lower levels of secondary education enrollment.

The results for the interaction of annual maternity compensation with GDP per capita for both infant and under-five mortality echo those seen for fertility. As GDP per capita increases, the negative effect of maternity compensation on mortality rates moves closer to zero. This

\footnotetext{
${ }^{25}$ Though individual parameter estimates do not appear to reach the usual $\mathrm{p}<0.05$ threshold of statistical significance, the collective parameters of each interaction shown were all significant when subject to a Wald test.

${ }^{26}$ When countries reach the highest levels of GDP per capita in our sample, any maternity leave policy and a leave policy with a duration of $12+$ weeks also predicts slightly increased rates of infant and under-five mortality, something that we argue could be due to the increased fertility rates in countries that still may not have advanced health systems for maternal and child health.
} 
means that the predicted reduction of both forms of mortality associated with maternity compensation is largest in the lowest income countries. An example of this pattern for infant mortality shown in Figure 2. As a country develops economically, the beneficial effects of maternity compensation on infant mortality are reduced such that by the time a country exceeds the median value of GDP per capita the marginal effect of maternity compensation is not significantly different from zero. This same pattern emerges in the case of under-five mortality. Again, we see support for our hypothesis that maternity provisions are most beneficial to the lowest-income countries, typically those with high infant and child mortality rates. In random effects model specifications (not shown), this moderating effect of GDP on maternity compensation's effect on mortality holds - suggesting that GDP plays a moderating role on the effect of maternity leave not only within countries, but also between countries.

In the case of both infant and under-five mortality, the models showing the interaction of maternity compensation and secondary enrollment diverge from what we see with fertility. Rather than having a strong negative effect at the lowest levels of secondary enrollment, both models show that maternity compensation's beneficial effects on mortality rates are evident in the middle range of secondary enrollment rate. Thus, at the lowest and highest levels of secondary education, the effects of maternity leave are not significantly different from zero, while in the mid-range of enrollments there is a negative influence of compensation on mortality rates. For instance, Figure 2 shows the interaction of annual maternity compensation with enrollment to moderate its effect on under-five mortality and indicates that in the range of 20-70 percent secondary enrollment, we see the significant negative effect of maternity compensation on child mortality. The result for infant mortality are similar in that the effect of maternity compensation is evident only in the mid-range of secondary enrollment. These results thus 
support our contention that maternity leave policies and compensation matter more for mortality rates in countries that have yet to reach the highest levels of secondary enrollment. Yet, in the case of these mortality rates, we need to add the caveat that the beneficial effects of maternity provision only manifest in countries once they have established at least 20 percent (in the case of under-five mortality) or approximately 40 percent secondary enrollment (in the case of infant mortality). Countries at the lowest levels of secondary enrollment do not experience benefits of maternity compensation when it comes to mortality rates.

Our interaction results show strong support for our moderation hypotheses. With 22 of 24 possible interaction effects indicating the moderating effects of economic development and education, we demonstrate that maternity leave and compensation levels are most beneficial to the poorest and least-educated countries.

\section{DISCUSSION}

Research on whether maternity leave provisions benefit developing countries is limited.

Our study seeks to add to existing case studies and limited cross national studies within developing countries by examining the effects of maternity leave on labor force participation, infant/child mortality, and fertility levels over four time points - with attention given to the moderating effects of GDP per capita and secondary school enrollment. We find that the effects of maternity provisions do indeed differ across developing countries, often due to the type of maternity leave implemented and to the disparities in economic and social development. We begin by discussing the non-findings of labor force participation before turning to the significant findings tied to fertility and mortality rates. 


\section{Understanding Non-Findings: Labor Force Participation}

Maternity provisions do not appear to increase female labor force participation across developing countries. This finding supports numerous qualitative case studies that suggest that women do not gain from maternity leave provisions because their access is limited due to employment sector (Bernasek and Gallaway 1997; Ilkkaracan 2012; Mehdizadeh 2013). Specifically, maternity provisions would only benefit women within formal sector employment, where compensation is more likely to be enforced. Within developing countries, most women must work, whether in the formal or informal sector (Verick 2014). If women are already working, then improvements in maternity benefits will not increase their labor force participation. Instead, there may be a shift from informal to formal sector employment, if the benefits are evident. Although this shift would change the structure of the labor force, it would leave the participation rate intact. The non-finding of labor force participation, then, is not surprising given the work patterns found within developing country contexts.

\section{General Findings: Maternity Leave Provisions}

The implementation of maternity leave policies in developing countries leads to decreases in fertility levels, and infant/child mortality rates, as hypothesized. Fertility is expected to decline in countries that have higher weekly paid compensation, whereas both infant and child mortality rates are expected to decline in countries that institute any leave policy, policies that last 12 weeks or longer, and policies that increase in duration and payment as a percentage of total annual salary. Although maternity leave policies do lead to decreases in fertility when considering weekly compensation, policies appear to have a greater effect on infant and child mortality rates when considering duration of leave and annual compensation of leave. For 
example, the same 25 percentage point increase in weekly salary compensation (one standard deviation) predicts a reduction of only one eighth of a birth in fertility rate, but reduces underfive mortality by more than nine deaths per 1,000. The findings regarding both infant and child mortality both support and expand upon the study presented by Nandi et al (2016), who find that increases in paid maternity leave duration lead to decreases in infant and child mortality among 20 lower and middle income countries. Our study shows that not only does duration matter, but the amount of compensation also contributes. We further add to the study by demonstrating that our results hold across 121 developing countries and that GDP per capita and secondary educational enrollment moderate the effects of maternity benefits. Our findings thus suggest that the type of maternity policy and the goals of the country (decreasing fertility versus infant/mortality rates) should be considered when implementing leaves within developingcountry contexts. Additionally, these general benefits of maternity leave need to be considered in tandem with the moderating effects of economic (GDP per capita) and social development (secondary educational enrollments).

\section{GDP per Capita:}

Countries with the lowest levels of GDP per capita are expected to benefit most from the implementation of maternity provisions. Countries that range from low to median GDP per capita are predicted to experience decreases in fertility with the implementation of maternity leave policies, in comparison to countries above median GDP per capita. Those with lower GDP per capita are thus expected to accrue the greatest benefit from these policies. The patterns are similar for infant mortality rates and child mortality rates. Yet, when countries reach the highest levels of GDP per capita in our sample, any maternity leave policy and a leave policy with a 
duration of $12+$ weeks also predict slightly increased rates of infant and under-five mortality, something that we argue could be due to the increased fertility rates in countries that still may not have advanced health systems for maternal and child health. Interestingly, once compensation is accounted for, increases in mortality and fertility rates are no longer predicted. These findings therefore suggest that countries with the lowest GDP per capita have the most to gain from when implementing maternity provisions. With job security, women are given the time to care for their children, leading to improvements in infant and child mortality rates. Similarly, women no longer need to have many children to compensate for lack of financial security leading to a decrease in fertility rates. These findings further suggest that different types of maternity provisions, particularly those that account for compensation, should be considered when attempting to address infant/child mortality and fertility rates.

\section{Secondary Educational Enrollments:}

When examining the moderating effects of secondary enrollment on maternity leave polices, we find that the patterns differ for fertility rates in comparison to infant and under-five mortality rates. Fertility patterns mirror similar outcomes for the moderating effect of GDP per capita. Countries with the lowest levels of secondary enrollment are predicted to experience the greatest drops in fertility, as maternity compensation increases. However, once secondary enrollment rates reach the 50 percent threshold, increases in maternity benefits no longer predict significant drops in fertility, and any maternity leave policy and policies of $12+$ weeks predict increases in fertility levels above about 70\% enrollment (any leave) and 90\% (12+ weeks leave) respectfully. Yet, when compensation is accounted for increases in fertility levels are no longer predicted. We see that maternity provisions' impact on women with lower education levels results in increasing 
this group's labor force attachment and increasing the economic value of their time, decreasing the incentive to have more children. The impact of this attenuates after reaching around the 60 percent threshold since women are already displaying higher levels of labor force attachment and not having as many children. The findings are different when examining the secondary enrollment effects on infant and child mortality rates. In these cases, middle enrollment countries - those in the range between $40-80$ percent enrollment (infant mortality) and $20-70$ percent enrollment (under-five mortality) - are predicted to experience decreases in infant and child mortality rates, as maternity policies improve. These findings support previous studies that show that increased maternal education is central to improving child and infant mortality rates (Boyle et al. 2006; Subbarao and Raney 1995). It further suggests that women must have some base level of education, alongside good maternity benefits, before improvements in infant and child mortality rates take place. As secondary level enrollments reach a threshold of around 80 percent, we find that the predicted drop in infant and child mortality rates is no longer significant. This is not to say that infant and child mortality rates (as well as fertility rates) may not continue to drop after this threshold for other reasons. Rather, the drop will not be as great, as enrollment attenuates the effect of maternity benefits. Our findings therefore demonstrate the importance of implementing maternity leave provisions in countries when they reach midrange levels of secondary enrollment, where some women have enough education to benefit from the policies applied.

\section{Case Examples:}

Some country examples demonstrate how the implementation of maternity policies are tied to GDP per capita and secondary enrollment. In Kenya and Niger, countries that are both on 
the lower end of GDP per capita, with a mean of \$533USD (Kenya) and \$270 (Niger) in our sample, and have either a mid-range secondary educational enrollment average of 48.5 percent (Kenya) and or low enrollment of only 10 percent (Niger), we find that fertility, infant and child mortality decrease sharply following increases in maternity compensation. In Figure 3 we scale our data to measure change since 1994, fertility and mortality rates begin at a score of 100 percent in 1994 and significantly by 2012. Under-five mortality is more than halved in both cases.

\section{[FIGURE 3 ABOUT HERE]}

\section{[FIGURE 4 ABOUT HERE]}

Compare this to Costa Rica or Mauritius depicted in Figure 4, which fall within the higher segment of GDP per capita and secondary educational enrollment in our sample. Although both experience decreases in fertility and infant/child mortality, both only drop to approximately 65 percent of their 1994 starting point by 2012, as opposed to below 50 percent. To further contrast the role of maternity leave, which all the examples above have, Lesotho (bottom portion of Figure 3) provides a counter example, with no maternity leave. Although fertility rates decrease at a steady rate (though not as steeply as in Kenya and Niger), the mortality rates first increase and then slowly decrease, with infant mortality increasing again slightly in the last few years. Indeed, the institution and increasing compensation of a maternity policy also appears to have development benefits even in lower middle-income countries like Namibia. The bottom portion of Figure 4 shows a sharp decline in Namibian mortality rates following their adoption of maternity leave in 2004 and an increase in compensation level in 2009. These examples demonstrate that the application of maternity leave policies decrease fertility rates, infant and 
child mortality - and particularly among countries with lower GDP per capita and middle range secondary school enrollments.

\section{Conclusion}

Our findings demonstrate how the level of social and economic development complicates the effects of improved maternity provisions across developing countries. Unlike developed countries, improvements in maternity provisions do not increase women's labor force participation. Most developing countries already have high rates of women's labor force participation, whether in the formal or informal sector, and increases in maternity benefits do not change these patterns. Yet, regardless of the existence of the informal sector, developing countries gain from instituting maternity benefits. Fertility is expected to decline in countries that have higher weekly paid compensation, and both infant and child mortality rates are expected to decline - and at a faster rate than fertility - in countries that institute any leave policy, policies that last 12 weeks or longer, and policies that increase in duration and payment as a percentage of total annual salary. The complexity of social and economic development further becomes apparent when examining how the effects of maternity compensation vary across developing countries - based on secondary school enrollment and level of GDP per capita. Among countries with lower levels of national income and improved maternity compensation, infant/child mortality rates and fertility levels decrease. Similarly, among countries with lower secondary enrollment rates and better maternity provisions, fertility levels decrease. Among countries with mid-range secondary educational enrollment and better maternity leave policies, child and infant mortality also decrease. 
By moving beyond case studies and limited cross-national studies, we highlight broader patterns that explain differences across developing countries, as well as differences according to social, economic, and political indicators. We hope this study provides a starting point to not only build on existing research, but also to further engage these questions, which can continue to add to our knowledge about how maternity provisions contribute to social, economic, and political development in developing countries.

\section{References:}

Aassve, Arnstein and Trude Lappegard. 2009. "Childcare Cash Benefits and Fertility Timing in Norway." European Journal of Population-Revue Europeenne De Demographie 25(1): 67-88.

Aigner, Dennis J, and Glen Cain. 1977. "Statistical Theories of Discrimination in Labor Markets." Industrial and Labor Relations Review 30(2): 175-187.

Akgunduz, Yusuf. Emre, and Janneke Plantenga. 2013. "Labour Market Effects of Parental Leave in Europe." Cambridge Journal of Economics 37(4): 845-862.

Allison, Paul D. 2009. Fixed effects regression models. Vol. 160. SAGE publications.

Andersson, Gunnar. 1999. "Childbearing trends in Sweden 1961-1997." European Journal of Population-Revue Europeenne De Demographie 15(1): 1-24.

Andersson, Gunnar, Jan M. Hoem, and Ann-Zofie Duvander. 2006. "Social differentials in speed-premium effects in childbearing in Sweden." Demographic Research 14: 51-69.

Avendano Mauricio, Lisa F. Berkman Lisa.F., Agar Brugiavini, and Giacomo Pasini. 2015. "The long-run effect of maternity leave benefits on mental health: Evidence from European countries." Social Science and Medicine 132: 45-53.

Barro, Robert J., Jong Wha Lee. 2013. "A New Data Set of Educational Attainment in the World, 1950-2010." Journal of Development Economics 104: 184-198.

Batal, Malek, Choghik Boulghourjian, Ahmad Abdallah, and Rima Afifi. 2006. "Breast-feeding and feeding practices of infants in a developing country: a national survey in Lebanon." Public health nutrition 9(3): 313-319.

Baum, Charles L. and Christopher J. Ruhm. 2016. "The Effects of Paid Family Leave in California on Labor Market Outcomes." Journal of Policy Analysis and Management 35: 333-356. 
Berger, Lawrence M. and Jane Waldfogel. 2004. "Maternity leave and the employment of new mothers in the United States." Journal of Population Economics 17: 331-49.

Bernasek, Alexandra, and Julie Gallaway. 1997. "Who Gets Maternity Leave? The Case of Malaysia." Contemporary Economic Policy 15(2): 94-104.

Besamusca, Janna, Kea Tijdens, Maarten Keune, Stephanie Steinmetz. 2015. "Working Women Worldwide: Age Effects in Female Labor Force Participation in 117 Countries." World Developmnet 74: 123-141.

Boje, Thomas P. and Anders Ejranes. 2012. "Policy and Practice: The Relationship Between Family Policy Regime and Women's Labour Market Participation in Europe." International Journal of Sociology and Social Policy 32(9/10): 589-605.

Boyle, Michael H., Yvonne Racine, Katholiki Georgiades, Dana Snelling, Sungjin Hong, Walter Omariba, Patricia Hurley, and Purnima Rao-Melacini. 2006. "The Influence of Economic Development Level, Household Wealth and Maternal Education on Child Health in the Developing World." Social Science \& Medicine 63(8):2242-2254.

Bratti, Massimiliano. 2003. "Labour Force Participation and Marital Fertility of Italian Women: The Role of Education." Journal of Population Economics 16(3):525-554.

Buyinza, Faisal, and Eria Hisali. 2014. "Microeffects of Women's Education on Contraceptive Use and Fertility: The Case of Uganda.” Journal of International Development. 26 (6): 763-778.

Carneiro, Pedro, Katrine V. Løken, and Kjell G. Salvanes. 2015. “A Flying Start? Maternity Leave Benefits and Long-Run Outcomes of Children." Journal of Political Economy 123(2): 365-412.

Chang, Mariko Lin. 2004. "Growing Pains: Cross-National Variation in Sex Segregation in Sixteen Developing Countries.” American Sociological Review 69: 114-67

Chatterji, Pinka and Sara Markowitz. 2005. "Does the Length of Maternity Leave Affect Maternal Health.” Southern Economic Journal 72(1): 16-41.

Chen, Martha, Jennefer Sebstad, and Lesley O'Connell. 1999. "Counting the invisible workforce: the case of homebased workers." World development 27(3): 603-610.

Clark, Roseanne, Janet Shibley Hyde, Marilyn J. Essex, and Marjorie H. Klein. 1997. "Length of Maternity Leave and Quality of Mother-Child Interactions.” Child Development 68: 364383. 
Coley, Rebekah Levine and Caitlin McPherran Lombardi. 2013. "Does Maternal Employment Following Childbirth Support or Inhibit Low-Income Children's Long-Term Development?" Child Development 84(1): 178-97.

Dagher Rada K, Patricia M McGovern, and Bryan E Dowd. 2014. "Maternity leave duration and postpartum mental and physical health: implications for leave policies." Journal of Health Politics, Policy and Law 39 (2): 369-416.

Daku, Mark, Amy Raub, and Jody Heymann. 2012. "Maternal Leave Policies and Vaccination Coverage: A global Analysis.” Social Science \& Medicine 74 (2): 120-124.

De Henau, Jérôme, Danièle Meulders \& Síle O'Dorchai, S. 2011. "Maybe Baby: Comparing Partnered Women's Employment and Child Policies in the EU-15." Feminist Economics 16(1): 43-77.

Del Boca, D. and Locatelli, M. 2006. "The Determinants of Motherhood and Work Status: A Survey." IZA Discussion Paper No. 2414, Institute for the Study of Labor, Bonn.

Engelhardt, Henriette, Tomas Kogel, \& Alexia Prskawetz. 2004. "Fertility and women's employment reconsidered: A macro-level time-series analysis for developed countries, 1960-2000.” Population Studies-a Journal of Demography 58(1): 109-20.

Engster, Daniel, and Stensöta, Helena O. 2011. "Do Family Policy Regimes Matter for Children's Well-Being?" Social Politics: International Studies in Gender, State \& Society 18(1): 82-124.

Fagan, Colette and Helen Norman. 2012. "Trends and Social Divisions in Maternal Employment Patterns following Maternity Leave in the UK." International Journal Sociology and Social Policy 32 (9/10): 544-560.

Ferrarini, Tommy, and Thor Norström. 2010. "Family Policy, Economic Development and Infant Mortality: A Longitudinal Comparative Analysis." International Journal of Social Welfare. 19: S89-S102.

Galtry, Judith \& Callister, Paul. 2005. "Assessing the Optimal Length of Parental Leave for Child and Parental Well-Being." Journal of Family Issues 26(2): 219-46.

Gauthier, Anne. 2007. "The Impact of Family Policies on Fertility in Industrialized Countries: A Review of the Literature." Population Research and Policy Review 26(3): 323-346.

Genre, Veronique, Ramon Salvador, and Ana Lamo. 2010. “European Women: Why Do(n’t) They Work?” Applied Economics 42(12): 1499-1514.

Gerecke, Megan. 2013. "A Policy Mix for Gender Equality? Lessons from High-Income Countries." International Labour Organization - International Institute for Labour Studies. 1-65. 
Germain, Adrienne. 1975. "Status and Roles of Women as Factors in Fertility Behavior: A Policy Analysis." Studies in Family Planning 6:192-200.

Ginneken, Wouter. 2003. "Extending Social Security: Policies for Developing Countries.” International Labour Review. 142 (3): 277-294.

Goldin, Claudia. 1995. "The U-Shaped Female Labor Force Function in Economic Development and Economic History." Pp. 61-90 in Investment in Women's Human Capital and Economic Development. Chicago, IL: University of Chicago Press.

Gornick, Janet C., Marcia K. Meyers, and Katherin E. Ross. 1997. "Supporting the Employment of Mothers: Policy Variation Across Fourteen Welfare States." Journal of European Social Policy 7:45-70.

Gregg, Paul, Elizabeth Washbrook, Carol Propper and Simon Burgess. 2005. "The Effects of a Mother's Return to Work Decision on Child Development in the UK." The Economic Journal 115(501): F48-F80.

Hampel-Milagrosa, Aimée. 2011. The Role of Regulation, Tradition and Gender in Doing Business: Case Study and Survey Report on a Two-Year Research Project in Ghana. Bonn: German Development Institute.

Harriss-White, Barbara. 2010. "Work and Wellbeing in Informal Economies: The Regulative Roles of Institutions of Identity and the State." World Development 38(2): 170-183.

Hausmann, Ricardo, Laura D. Tyson, Yasmina Bekhouche, Saadia Zahidi. 2014. "The Global Gender Gap Index 2014." http://www3.weforum.org/docs/GGGR14/GGGRMainChapterAppendices_2014.pdf

Hennig Marina., Dörthe Gatermann D., and Anna Erika Hagglund. 2012. "Pros and Cons of Family Policies for Mothers' Labour Market Participation." International Journal of Sociology and Social Policy 32(9): 502-512.

Hoem, Jan M. 1993. "Public Policy as the Fuel of Fertility: Effects of a Policy Reform on the Pace of Childbearing in Sweden in the 1980s." Acta Sociologica 36(1): 19-31.

Hoem, Jan M., Prskawetz, Alexia, \& Neyer, Gerda. 2001. “Autonomy or Conservative Adjustment? The Effect of Public Policies and Educational Attainment on Third Births in Austria, 1975-96.” Population Studies 55(3): 249-261.

Hofferth, Sandra L., and Sally C. Curtin. 2006. "Parental Leave Statutes and Maternal Return to Work After Childbirth in the United States.” Work and Occupations 33(1): 73-105.

Ilkkaracan, Ipek. 2012. "Why So Few Women in the Labor Market in Turkey?" Feminist Economics 18(1): 1-37. 
ILO (International Labour Organization). 2011. “Definitions: Labour Force.” ILOSTAT Database https://www.ilo.org/ilostat/faces/home/statisticaldata/conceptsdefinitions?_adf.ctrl$\underline{\text { state }=1 \mathrm{ktewvudg} \_158 \& \text { clean }=\text { true \&_afrLoop }=276783440445488}$

------. 2013. "Conditions of Work and Employment Programme: Maternity Protection." Travail Legal Databases. http://www.ilo.org/dyn/travail/travmain.sectionChoice?p_structure=

-----. 2016. "Economically Active Population, Estimates, and Projections." LABORSTA Internet http://laborsta.ilo.org/applv8/data/EAPEP/eapep_E.html

Karaçam, Zekiye. 2008. "Factors Affecting Exclusive Breastfeeding of Healthy Babies Aged Zero to Four Months: A Community-Based Study of Turkish Women.” Journal of Clinical Nursing 17(3): 341-349.

Karshenas, Massoud, Valentine M. Moghadam, and Randa Alami. 2014. "Social Policy after the Arab Spring: States and Social Rights in the MENA Region." World Development 64: 726-739.

Keck, Wolfgang and Chiara Saraceno. 2013. "The Impact of Different Social -Policy Frameworks on Social Inequalities among Women in the European Union: The LabourMart Participation of Mothers." Social Politics 20(3): 297-328.

Khanam Rasheda, Son Nghiem, and Luke Connelly. 2016. "The effects of parental leave on child health and postnatal care: Evidence from Australia." Economic Analysis and Policy. 49: 17-29.

Klerman, Jacob A. and Aileen Leibowitz, A. 1999. "Job Continuity among New Mothers." Demography 36: 145-55.

Korpi, Watler, Tommy Ferrarini, and Stephan Englund. 2013. "Women's Opportunities under Different Family Policy Constellations: Gender, Class, and Inequality Tradeoffs in Western Countries Re-examined." Social Politics: International Studies in Gender, State \& Society. 20(1): 1-40.

Lalive, Rafael and Josef Zweimueller, J. 2009. "How Does Parental Leave Affect Fertility and Return to Work? Evidence from Two Natural Experiments." The Quarterly Journal of Economics 124(3): 1363-402.

Lee, Kye Woo, and Kisuk Cho. 2005. "Female labour force participation during economic crises in Argentina and the Republic of Korea." International Labour Review 144(4): 423-450.

Lincove, Jane Arnold. 2008. "Growth, Girls' Education, and Female Labor: A Longitudinal Analysis." The Journal of Developing Areas 41(2): 45-68. 
Lipton, Michael and Martin Ravallion. 1995. "Poverty and Policy." Handbook of Development Economics 3(2): 2551-2657.

Loayza, Norman and James Rigolini. 2006. "Informality Trends and Cycles." The World Bank. Research Paper.

Low, Hamish, and Virginia Sánchez-Marcos. 2015. "Female labour market outcomes and the impact of maternity leave policies." IZA Journal of Labor Economics. 4 (1): 1-22.

Mandel, Hadas. 2010. "Winners and Losers: The Consequences of Welfare State Policies for Gender Wage Inequality.” European Sociological Review: 28(2): 241-262.

Mandel, Hadas, and Moshe Semyonov. 2006. "A Welfare State Paradox: State Interventions and Women's Employment Opportunities in 22 Countries." American Journal of Sociology 20(1): $1910-49$.

Matysiak, Anna and Dorota Weziak-Bialowolska. 2013. "Country-Specific Conditions for Work and Family Reconciliation: An Attempt at Quantification." Institute of Statistics and Demography 31: 1-42.

Mehdizadeh, Narjes. 2013. "Measures to Promote Work-Family Reconciliation in the MENA region: Parental Leave, Childcare, and Good Practices." Doha International Family Institute: Family Research and Proceedings 1-21.

Milligan, Kevin. 2002. “Quebec's Baby Bonus: Can Public Policy Raise Fertility?” CD. Howe Institute. Backgrounder. http://www.cdhowe.org/pdf/Milligan_Back- grounder.pdf

Misra, Joya, Michelle Budig, and Irene Boeckmann. 2011. "Work-Family Policies and the Effects of Children on Women's Employment Hours and Wages." Community, Work \& Family 14(2): 139-157.

Musick, Kelly, Paula England, Sarah Edgington, and Nicole Kangas. 2009. "Education Differences in Intended and Unintended Fertility." Social Forces 88 (2): 543-572.

Nandi Arijit., Mohammad Hajizadeh, Sam Harper, Alissa Koski, Erin C. Strumpf, and Jody Heymann. 2016. "Increased Duration of Paid Maternity Leave Lowers Infant Mortality in Low- and Middle-Income Countries: A Quasi-Experimental Study." PLoS Medicine. 13 (3).

Orloff, Ann Shola. 2009. "Gendering the Comparative Analysis of Welfare States: An Unfinished Agenda." Sociological Theory 27(3): 317-343.

Pampel, Fred C., and Kazuko Tanaka. 1986. "Economic Development and Female Labor Force Participation: A Reconsideration.” Social forces 64(3): 599-619. 
Pettit, Becky and Jennifer Hook. 2005. "The Structure of Women's Employment in Comparative Perspective." Social Forces 84(2): 779-801.

Rønsen, Marit and Marianne Sundström. 2002. "Family Policy and After-Birth Employment Among New Mothers - A Comparison of Finland, Norway and Sweden.” European Journal of Population / Revue européenne de Démographie 18 (2): 121-52.

Ruhm, Christopher J. 1998. "The Economic Consequences of Parental Leave Mandates: Lessons from Europe.” Quarterly Journal of Economics 113(1):207-25.

-----. 2000. “Parental leave and child health.” Journal of Health Economics 19(6): 931-960.

Sen, Amartya. 1999. Development as Freedom. New York: Alfred A. Knopf.

Shapiro, David, and Frank Mott. 1994. "Long-Term Employment and Earnings of Women in Relation to Employment Behavior Surrounding the First Birth." Journal of Human Resources 29(2): 248-275.

Staehelin, Katharina, Paola Coda Bertea, Elisabeth Zemp Stutz. 2007. "Length of maternity Leave and Health of Mother and Child - A Review." International Journal of Public Health 52(4): 202-209.

Steiber, Nadia, and Barbara Haas. 2012. "Advances in Explaining Women's Employment Patterns.” Socio-economic Review 10(2): 343-3.

Subbarao, Kalanidhi and Laura Raney. 1995. "Social Gains from Female Education: a CrossNational Study.” Economic Development and Cultural Change 44:105-128.

Tanaka, Sakiko. 2005. "Parental Leave and Child Health Across OECD Countries." The Economic Journal 115(501): F7-F28.

Thévenon, Olivier. 2008. "Family Policies in Europe: Available Databases and Initial Comparisons." Vienna Yearbook of Population Research, 165-177.

Thévenon, Olivier and Anne H. Gauthier. 2011. "Family Policies in Developed Countries: a 'Fertility-Booster' with Side-Effects.” Community, Work \& Family 14(2): 197-216.

Thévenon, Olivier and Anne Solaz 2013. "Labour Market Effects of Parental Leave Policies in OECD Countries." OECD Social, Employment and Migration Working Papers, No. 141, OECD Publishing.

Tomaskovic-Devey, Donald. 1993. Gender \& Racial Inequality at Work: The Sources and Consequences of Job Segregation. Ithaca, N.Y: ILR Press.

Tzannatos, Zafiris. 1999. "Women and Labor Market Changes in the Global Economy: Growth Helps, Inequalities Hurt and Public Policy Matters.” World Development 27(3): 551-569. 
United Nations. 2015. "United Nation Sustainable Development Goals." Transforming Our World - the 2030 Agenda for Sustainable Development https://sustainabledevelopment.un.org/?menu=1300

Van der Meulen-Rodgers, Yana. 1999. "Protecting Women and Promoting Equality in the Labor Market: Theory and Evidence." Policy Research Report on Gender and Development Working Paper Series, No. 6. Washington, DC: The World Bank.

Verick, Sher. 2014. "Female labor force participation in developing countries." International Labour Organization, India, and IZA, Germany. http://wol.iza.org/articles/female-laborforce-participation-in-developing-countries.pdf

Victoria, Cesar G., Adam Wagstaff, Joanna Armstrong Schellenberg, Davidson Gwatkin, Mariam Claeson, and Jean-Pierre Habicht. 2003. "Applying an Equity Lens to Child Health and Mortality: More of the Same Is Not Enough.” The Lancet 362(9379): 233-41.

Victoria Cesar G. Estela M Aquino, Maria do Carmo Leal M, Carlos A Monteiro, Fernando C Barros, and Celia L Szwarcwald. 2011. "Maternal and Child Health in Brazil: Progress and Challenges." Lancet 377 (9780): 1863-7.

Vikat, Andres. 2004. "Women's labor force attachment and childbearing in Finland." Demographic Research 3(8): 175-212.

Waldfogel, Jane. 1998. "Understanding the 'Family Gap' in Pay for Women with Children." Journal of Economic Perspectives 12: 137-156.

Wekwete, Naomi Netsayi. 2014. "Gender and Economic Empowerment in Africa: Evidence and Policy." Journal of African Economies 23(1): 87-127.

Wickrama, K.A.S., and Frederick O. Lorenz. 2002. "Women's Status, Fertility Decline, and Women's Health in Developing Countries: Direct and Indirect Influences of Social Status on Health." Rural Sociology. 67 (2): 255-277.

Williams Colin C. 2014. "Out of the Shadows: A Classification of Economies by the Size and Character of their Informal Sector." Work, Employment and Society. 28 (5): 735-753.

World Bank. 1995. World Development Report 1995: Workers in an Integrating World. New York: Oxford University Press.

------. 2011. “Gini Index: World Bank Estimate.” http://data.worldbank.org/indicator/ SI.POV.GINI

------. 2012. World Development Report, 2012. Gender equality and Development. Washington: World Bank. 
-----. 2015. “World Development Indicators." http://data.worldbank.org/products/wdi

-----. 2016. "GDP Per Capita Current US Dollars." http://data.worldbank.org/indicator/NY.GDP.PCAP.CD?end=2012\&start=1960

Zveglich, Jr., Joseph E., and Yana Van der Meulen Rodgers. 2003. "The Impact of Protective Measures for Female Workers." Journal of Labor Economics 21(3): 533-555. 
Table 1. Summary Statistics

\begin{tabular}{lcccccc} 
& mean & median & min & max & sd & N \\
\hline & & & & & & \\
INDEPENDENT VARIABLES & & & & & & \\
\hline Maternity leave duration (weeks) & 13.4 & 13 & 4 & 52 & 4.45 & 393 \\
Maternity leave compensation (\% paid weekly) & 85.1 & 100 & 0 & 100 & 24.8 & 378 \\
Maternity Leave Compensation (\% of annual salary) & 22.0 & 23.1 & 0 & 55.4 & 8.96 & 378 \\
\hline & & & & & & \\
DEPENDENT VARIABLES & & & & & & \\
\hline Fertility rate, total (births per woman), 5-year lead & 3.51 & 3.06 & 1.16 & 7.74 & 1.67 & 566 \\
Labor Force Participation (females 15-49), 5-year lead & 53.1 & 52.3 & 11 & 88.4 & 17.7 & 553 \\
Infant mortality rate (per 1,000), 5-year lead & 42.4 & 31.8 & 2.50 & 144.2 & 31.1 & 573 \\
Mortality rate, under-5 (per 1,000), 5-year lead & 61.2 & 40.2 & 3 & 241.1 & 52.2 & 573 \\
\hline & & & & & & \\
CONTROL VARIABLES & & & & & & \\
\hline Net ODA per capita (constant 2011 dollars) & 89.3 & 46.1 & -12.6 & 6420.9 & 299.7 & 573 \\
Logged GDP per capita (constant 2005 dollars) & 7.29 & 7.29 & 4.80 & 9.85 & 1.19 & 573 \\
School enrollment, secondary (\% gross) & 56.8 & 58.2 & 4.98 & 163.0 & 30.3 & 573 \\
Polity IV Score & 2.80 & 5 & -10 & 10 & 6.14 & 573 \\
Health expenditure, total (\% of GDP) & 5.56 & 5.36 & 2.06 & 13.1 & 1.91 & 573 \\
\hline
\end{tabular}


Table 2. Fixed Effects Regression of the Effects of Maternity Leave on Fertility Rate \& Female Labor Force Participation, $1999-2012$

\begin{tabular}{|c|c|c|c|c|}
\hline & \multicolumn{2}{|c|}{$\begin{array}{c}\text { Female Labor Force } \\
\text { Participation }\end{array}$} & \multicolumn{2}{|c|}{ Fertility Rate } \\
\hline & (1) & (2) & (3) & (4) \\
\hline \multicolumn{5}{|l|}{ Maternity Leave Measures } \\
\hline Any leave policy (dummy) & 0.017 & & & \\
\hline Leave compensation (\% paid weekly) & & & $-0.005^{*}$ & $-0.007 * *$ \\
\hline Leave compensation ( $\%$ annual salary) & & 0.061 & & \\
\hline \multicolumn{5}{|l|}{ Controls } \\
\hline Polity IV Score & 0.071 & 0.095 & -0.004 & -0.011 \\
\hline Aid per capita & $-0.010^{* *}$ & $-0.014 * *$ & $0.001 *$ & 0.001 \\
\hline GDP per capita $(\log )$ & & -0.684 & & $-0.458 * * *$ \\
\hline Secondary school enrollment & $0.080 * * *$ & & $-0.017 * * *$ & \\
\hline Health expenditure ( $\%$ of GDP) & -0.129 & $0.441^{\wedge}$ & -0.020 & $-0.056^{*}$ \\
\hline Constant & $54.423 * * *$ & $59.065^{* * *}$ & $4.979 * * *$ & $7.750^{* * *}$ \\
\hline Observations & 553 & 372 & 377 & 377 \\
\hline Countries & 114 & 103 & 106 & 106 \\
\hline R2 Overall & 0.024 & 0.052 & 0.670 & 0.528 \\
\hline R2 Within & 0.101 & 0.060 & 0.387 & 0.237 \\
\hline R2 Between & 0.028 & 0.058 & 0.696 & 0.551 \\
\hline
\end{tabular}

${ }^{\wedge} \mathrm{p}<0.1,{ }^{*} \mathrm{p}<0.05,{ }^{* *} \mathrm{p}<0.01,{ }^{* * *} \mathrm{p}<0.001$ 
Table 3. Fixed Effects Regression of the Effects of Maternity Leave on Infant and Under-5 Mortality, 1999-2012

Infant Mortality

$$
\text { (1) }
$$

(2)

$-1.387^{*}$

Maternity Leave Measures

Any leave policy (dummy)

Leave 12 weeks+ (dummy)

Leave compensation (\% paid weekly)

Leave compensation ( $\%$ annual salary)

\section{Controls}

Polity IV Score

Aid per capita

GDP per capita $(\log )$

Secondary school enrollment

Health expenditure (\% of GDP)

Constant

Observations

Countries

R2 Overall

R2 Within

R2 Between

\section{$-0.454 *$}

0.001

$-0.487 *$

$0.029 *$

$-0.519 *$

$0.045 * *$

$-0.401 * * * \quad-0.423 * * * \quad-0.419 * * *$

$\begin{array}{lll}-1.236^{*} & -1.434^{*} & -1.195^{\wedge}\end{array}$

$74.170 * * * \quad 77.198 * * * \quad 80.559 * * *$

$116.970 * * *$

Under-5 Mortality

\begin{tabular}{llll}
\hline$(4)$ & $(5)$ & $(6)$ & $(7)$ \\
\hline
\end{tabular}

$-2.521^{*}$

$-7.411 *$

$-0.363^{*}$

$-0.889 *$

$\begin{array}{llll}-1.166^{*} & -1.291 * & -1.357 * & -1.133^{*}\end{array}$

$0.003 \quad 0.063 * 0.086^{*} \quad 0.100 * *$

$-33.434 * * *$

$-0.682 * * *$

$\begin{array}{llll}-0.651 * * * & -0.684 * * * & & -0.682^{* * *} \\ -2.519 * & -3.041^{*} & -3.072^{*} & -2.442^{\wedge}\end{array}$

$-3.041 *-3.072 *-2.442$

$116.970 * * * \quad 120.065 * * * \quad 352.890 * * * \quad 130.675 * * *$

\begin{tabular}{ccccccc}
573 & 452 & 378 & 573 & 452 & 378 & 378 \\
121 & 121 & 106 & 121 & 121 & 106 & 106 \\
0.575 & 0.432 & 0.627 & 0.542 & 0.349 & 0.520 & 0.553 \\
0.303 & 0.344 & 0.347 & 0.248 & 0.282 & 0.317 & 0.287 \\
0.586 & 0.236 & 0.649 & 0.565 & 0.158 & 0.547 & 0.586 \\
\hline
\end{tabular}


Table 4. Fixed Effects Regression of the Interaction Effects of Maternity Leave on Fertility \& Mortality, 1999-2012

\begin{tabular}{|c|c|c|c|c|c|c|}
\hline & \multicolumn{2}{|c|}{ Fertility } & \multicolumn{2}{|c|}{$\begin{array}{l}\text { Infant } \\
\text { Mortality }\end{array}$} & \multicolumn{2}{|c|}{ Under-5 Mortality } \\
\hline & $(1)$ & $(2)$ & (3) & $(4)$ & $(5)$ & $(6)$ \\
\hline \multicolumn{7}{|l|}{ Maternity Leave Measures } \\
\hline Leave compensation ( $\%$ weekly salary) & -0.014 & $-0.007 *$ & & & & \\
\hline $\begin{array}{l}\text { Leave compensation ( } \% \text { weekly salary) X GDP per capita } \\
(\log )\end{array}$ & 0.001 & & & & & \\
\hline Leave compensation (\% weekly salary) X Enrollment & & 0.000 & & & & \\
\hline Leave compensation ( $\%$ annual salary) & & & $-3.007 * *$ & -0.572 & $-7.841 * *$ & $-1.839^{\wedge}$ \\
\hline $\begin{array}{l}\text { Leave compensation ( } \% \text { annual salary) X GDP per capita } \\
(\log )\end{array}$ & & & $0.352 *$ & & $0.942 * *$ & \\
\hline Leave compensation (\% annual salary) X Enrollment & & & & 0.003 & & 0.016 \\
\hline \multicolumn{7}{|l|}{ Controls } \\
\hline Polity IV Score & -0.011 & -0.005 & $-0.615^{* *}$ & $-0.520 *$ & $-1.241 *$ & $-1.142 *$ \\
\hline Aid per capita & 0.001 & $0.001 *$ & $0.034^{\wedge}$ & $0.046^{* *}$ & $0.082 *$ & $0.107 * *$ \\
\hline GDP per capita $(\log )$ & $-0.562 * *$ & & $-29.129 * * *$ & & $-55.100 * * *$ & \\
\hline Secondary school enrollment & & $-0.020 * * *$ & & $-0.471 * *$ & & $-0.986 * *$ \\
\hline Health expenditure ( $\%$ of GDP) & $-0.055^{*}$ & -0.019 & $-1.462 *$ & $-1.193^{\wedge}$ & $-2.824^{*}$ & $-2.429^{\wedge}$ \\
\hline Constant & $8.423 * * *$ & $5.104 * * *$ & $272.172 * * *$ & $83.419 * * *$ & $498.166^{* * *}$ & $147.297 * * *$ \\
\hline Observations & 377 & 377 & 378 & 378 & 378 & 378 \\
\hline Countries & 106 & 106 & 106 & 106 & 106 & 106 \\
\hline R2 Overall & 0.533 & 0.669 & 0.558 & 0.623 & 0.503 & 0.532 \\
\hline R2 Within & 0.239 & 0.389 & 0.416 & 0.348 & 0.349 & 0.296 \\
\hline R2 Between & 0.557 & 0.697 & 0.591 & 0.647 & 0.541 & 0.563 \\
\hline
\end{tabular}

${ }^{\wedge} \mathrm{p}<0.1,{ }^{*} \mathrm{p}<0.05, * * \mathrm{p}<0.01,{ }^{* * *} \mathrm{p}<0.001$ 
Figure 1. Moderating Effect of Economic Development on the Marginal Effects of Maternity Leave Measures on Mortality and Fertility

Marginal Effect of Any Maternity Leave Policy
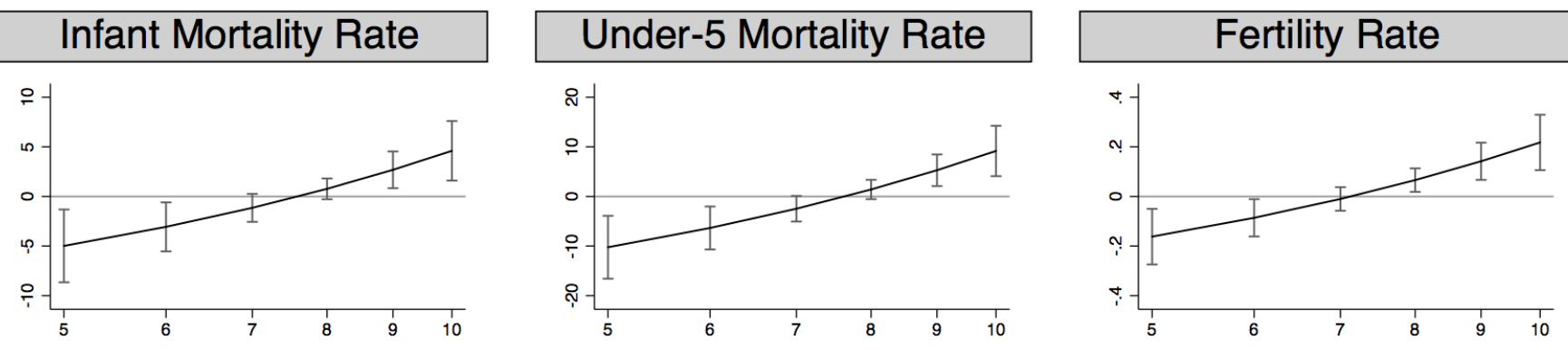

\section{Marginal Effect of Maternity Leave of 12 weeks+}
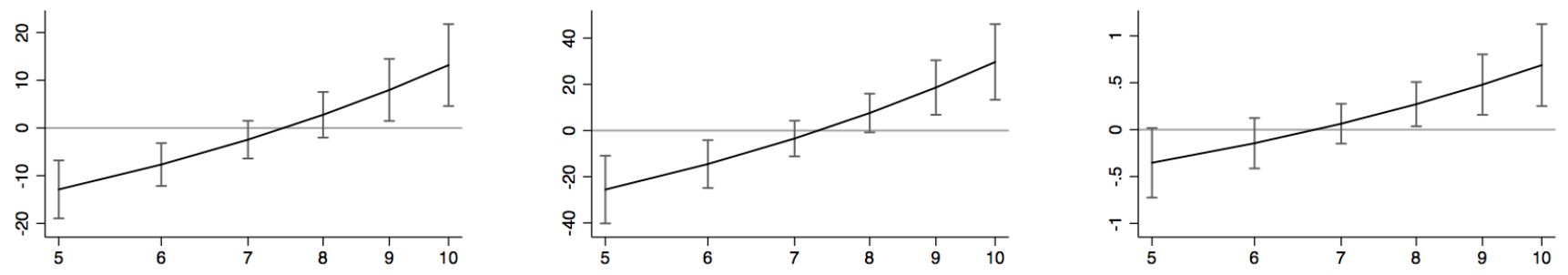

Marginal Effect of

Weekly Maternity Compensation
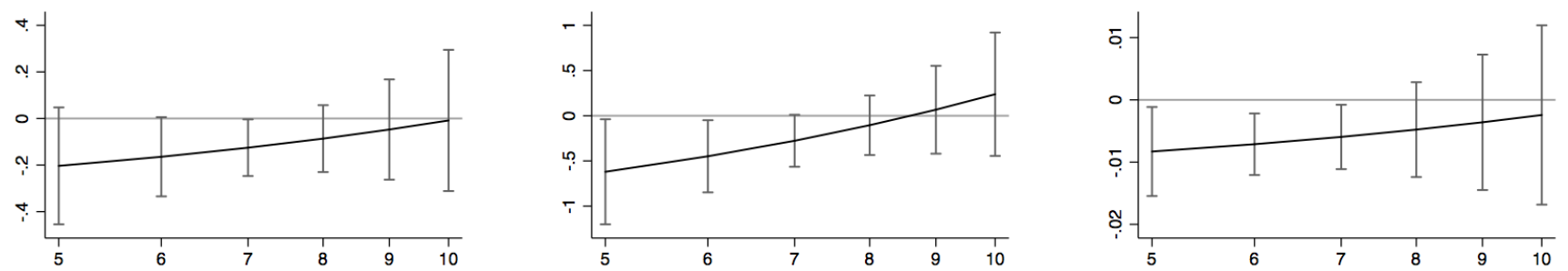

Marginal Effect of Annual Maternity Compensation
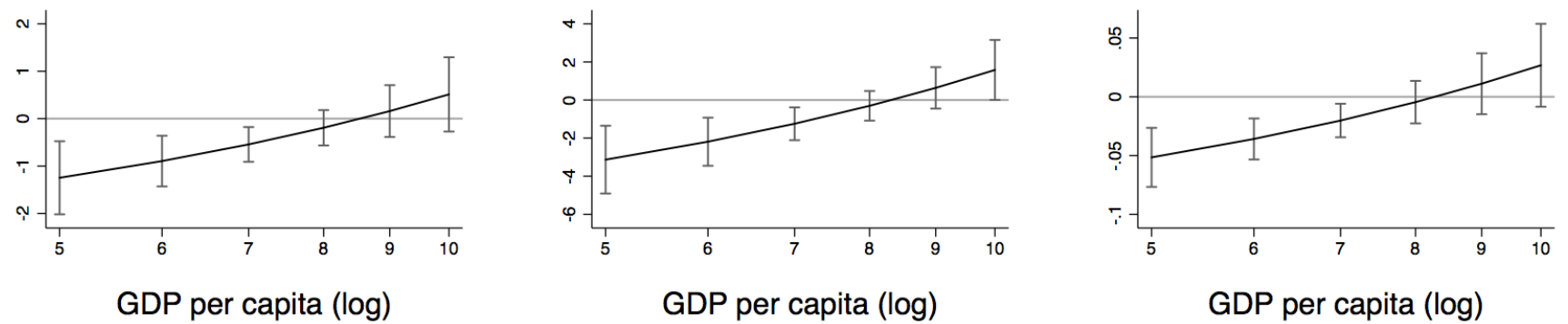
Figure 2. Moderating Effect of Education on the Marginal Effects of Maternity Leave Measures on Mortality and Fertility

Marginal Effect of

Any Maternity

Leave Policy
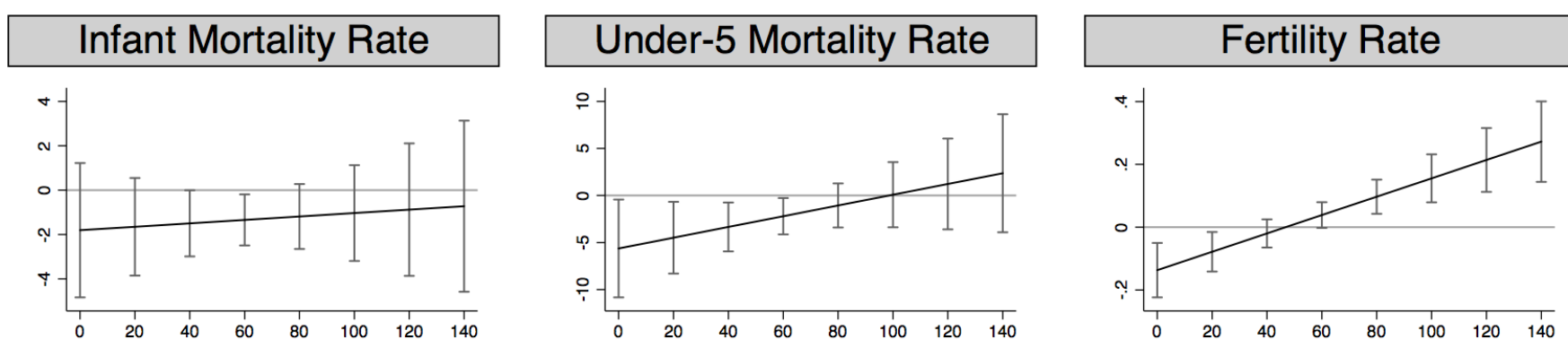

Marginal Effect of
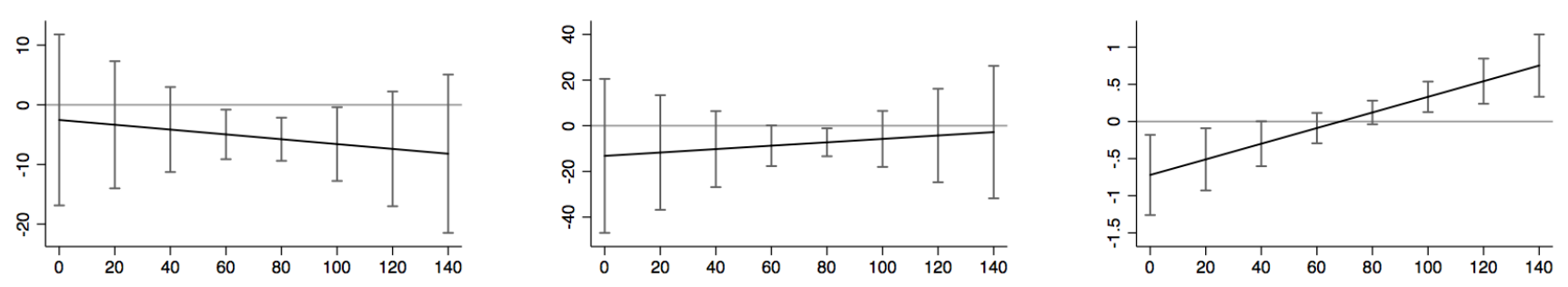

Marginal Effect of

Weekly Maternity

Compensation

Marginal Effect of

Annual Maternity Compensation

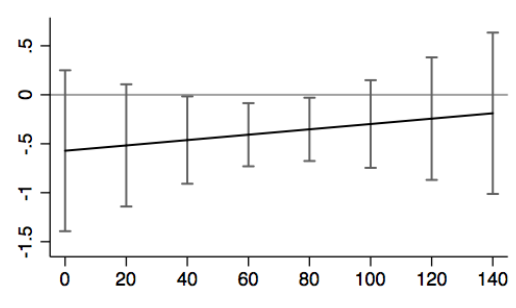

Secondary school enrollment

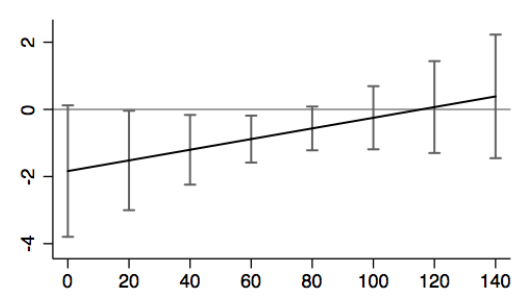

Secondary school enrollment
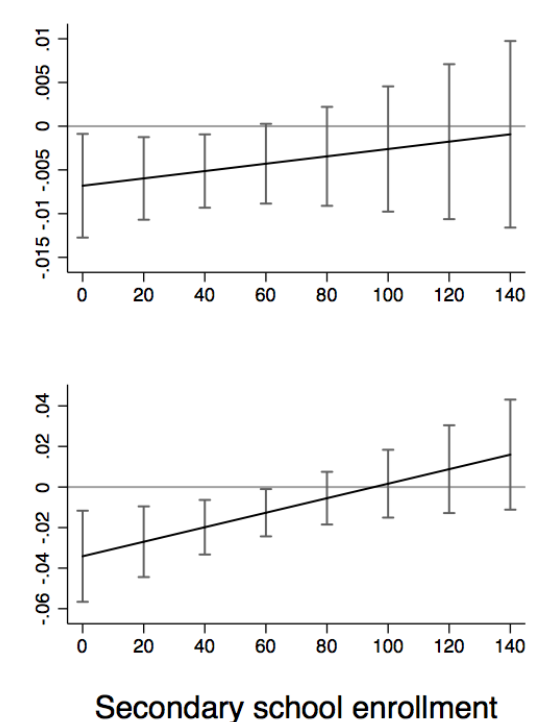
Figure 3. Change in Fertility and Mortality Rates and Maternity Compensation, Low-Income Exar.

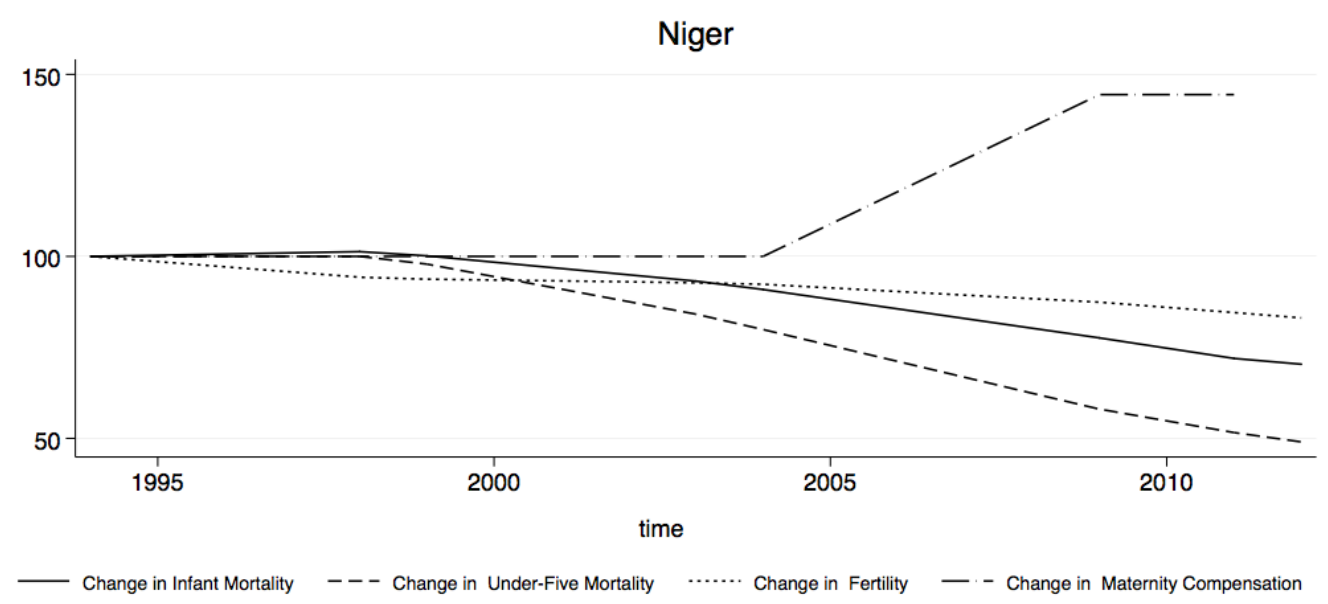
Note: First observation $=100$

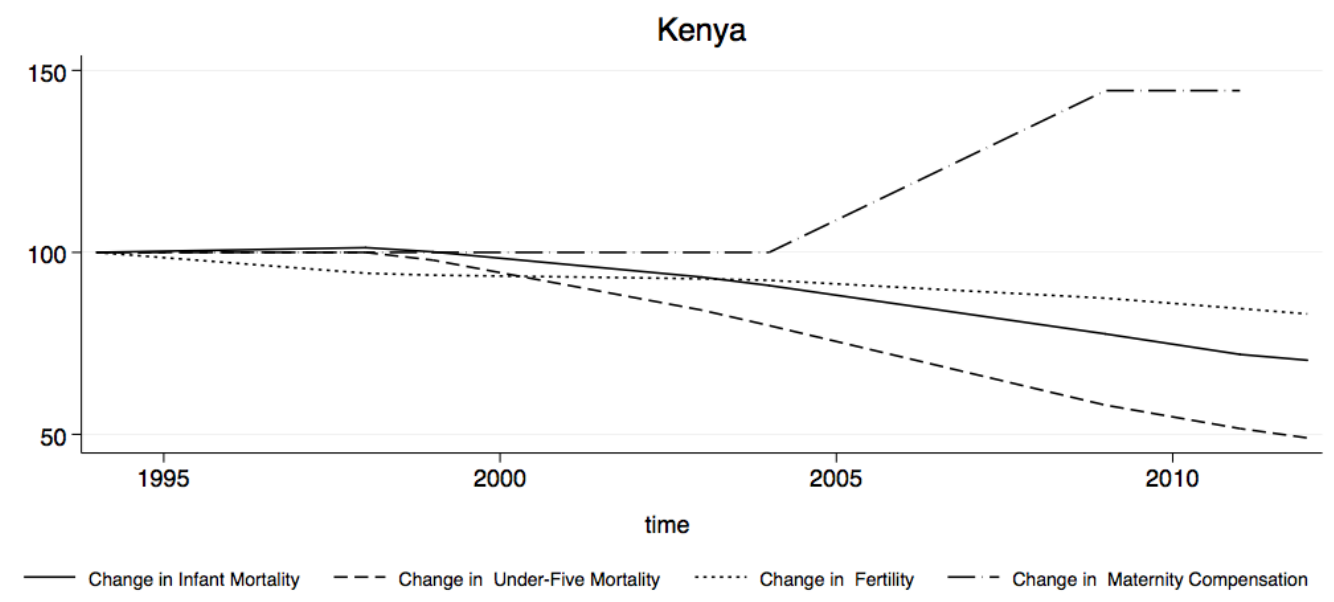
Note: First observation $=100$

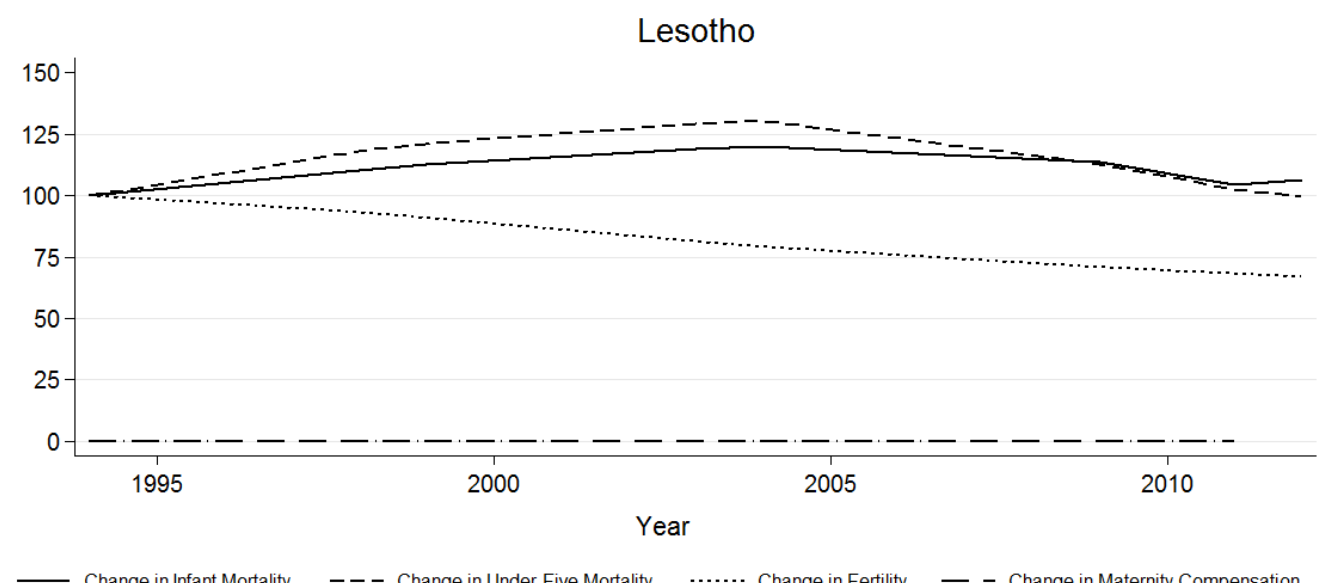
Note: First observation $=100$ 
Figure 4. Change in Fertility and Mortality Rates and Maternity Compensation, Middle-Income Examples

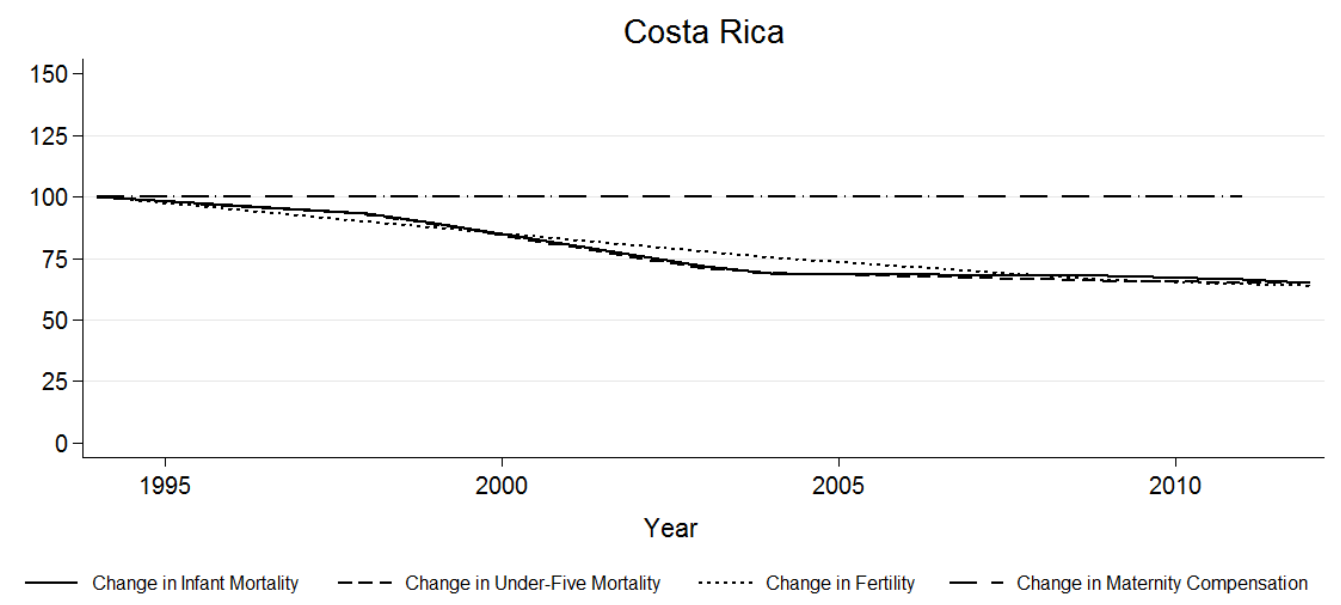
Note: First observation $=100$

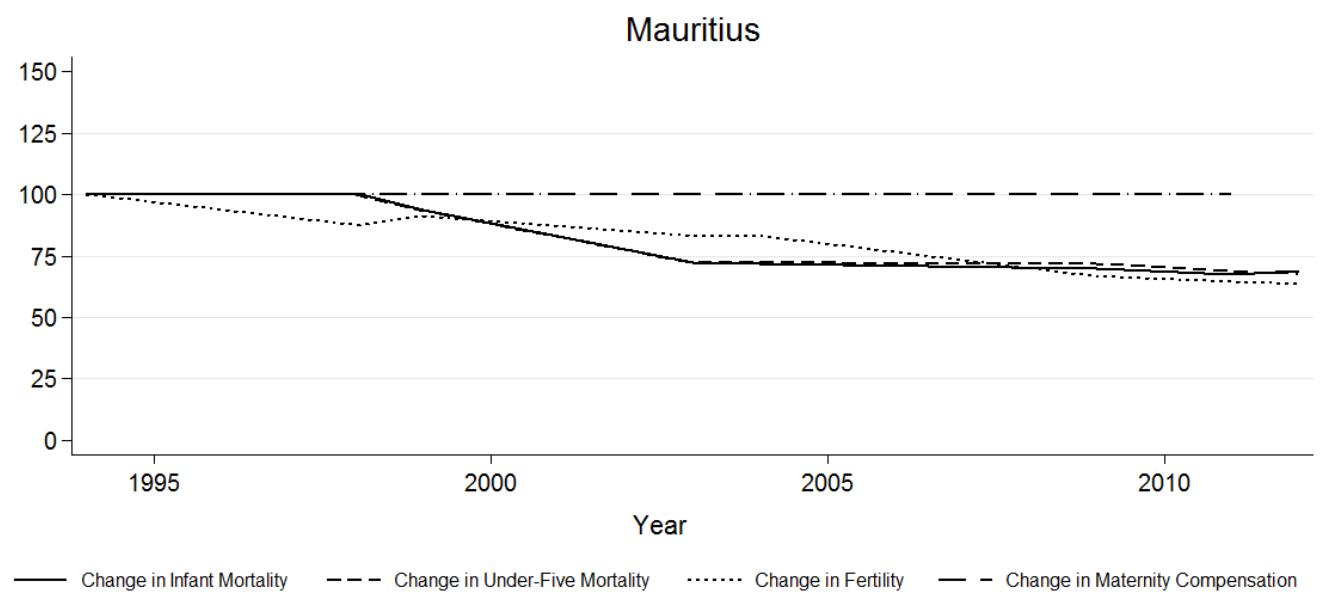
Note: First observation $=100$

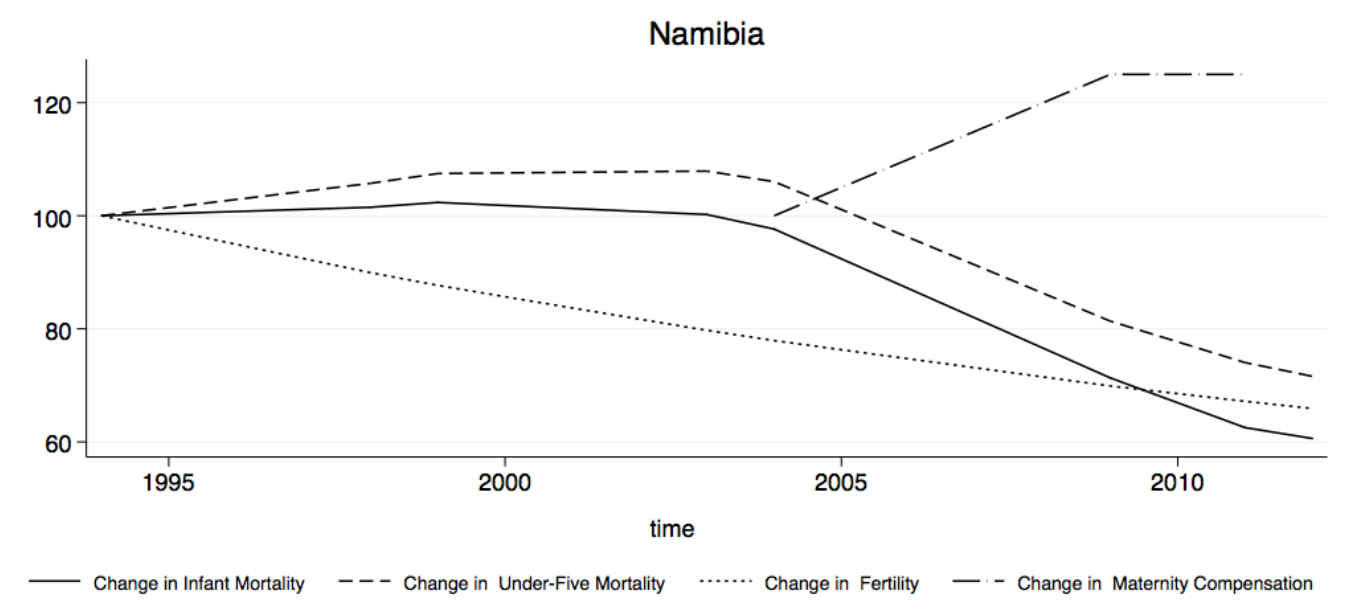
Note: First observation $=100$ 